\title{
Impact of the thermomechanical load on subsurface phase transformations during cryogenic turning of metastable austenitic steels
}

\author{
Hendrik Hotz ${ }^{1}\left[\right.$. Benjamin Kirsch ${ }^{1} \cdot$ Jan C. Aurich ${ }^{1}$
}

Received: 11 October 2019 / Accepted: 11 July 2020 / Published online: 22 July 2020

(c) The Author(s) 2020

\begin{abstract}
When machining metastable austenitic stainless steel with cryogenic cooling, a deformation-induced phase transformation from $\gamma$-austenite to $\alpha^{\prime}$-martensite can be realized in the workpiece subsurface. This leads to a higher microhardness and thus improved fatigue and wear resistance. A parametric and a non-parametric model were developed in order to investigate the correlation between the thermomechanical load in the workpiece subsurface and the resulting $\alpha^{\prime}$-martensite content. It was demonstrated that increasing passive forces and cutting forces promoted the deformation-induced phase transformation, while increasing temperatures had an inhibiting effect. The feed force had no significant influence on the $\alpha^{\prime}$-martensite content. With the proposed models it is now possible to estimate the $\alpha^{\prime}$-martensite content during cryogenic turning by means of in-situ measurement of process forces and temperatures.
\end{abstract}

Keywords Martensite $\cdot$ Cryogenic turning $\cdot$ Metastable austenitic steel $\cdot$ Deformation-induced phase transformation

\section{Introduction}

The surface integrity of a component significantly influences its performance in technical applications. In recent years, numerous investigations have been carried out to investigate the influence of the machining process on surface integrity. Brinksmeier et al. (2018) described a general causal sequence of correlations starting from the input parameter of the machining process to the resulting thermomechanical loads during machining, the surface integrity after machining and the resulting functional properties. An understanding of the individual correlations allows the targeted configuration of the surface integrity and thus the functional properties by specific adjustment of the input parameters, e.g. by means of variations of the cutting parameters, the cooling strategy or the tool design.

There are several approaches that allow to calculate the process forces (Sharma et al. 2008; Rodic et al. 2020) and

Hendrik Hotz

hendrik.hotz@mv.uni-kl.de

https://www.fbk-kl.de

1 Institute for Manufacturing Technology and Production Systems, TU Kaiserslautern, 67663 Kaiserslautern, Germany the temperatures (Komanduri \& Hou 2000; Huang \& Liang 2003) depending on the input parameter. Non-parametric models become increasingly established in manufacturing technology and allow to predict and improve the component properties (Choudhary et al. 2009). Xu et al. (2020) used artificial neural networks (ANN) to calculate the residual stresses and the surface roughness depending on the cutting parameter. Ji et al. (2019) reduced the thickness of the white layer in the workpiece subsurface in a big data approach. Recently, the investigation of soft-sensors in machining processes has gained importance. That is, when the correlations between the thermomechanical load and the resulting surface integrity have already been quantified, in-situ measurable values such as temperature and process forces can be used to determine the surface integrity already during the machining process. According to Uebel et al. (2019) the use of soft-sensors enables the in-situ detection of deviations in the thermomechanical load caused by disturbance variables (e.g. tool wear), which in turn would result in undesired deviations in the surface integrity. By knowing the causal correlations between input variables and the thermomechanical load, these undesired deviations can be compensated, e.g. by adjusting the cutting parameters, allowing for the manufacturing of components with uniform surface integrity. The prerequisite for the compensation of disturbance 
variables by means of a control loop is the quantification of the correlations between input parameter, thermomechanical load and surface integrity, as well as the in-situ measurement of the thermomechanical load.

After machining with geometrically defined cutting edges, an elongation of the grains in the cutting direction and a pronounced grain refinement can be observed below the workpiece surface for a wide range of materials, as reported by Jawahir et al. (2011) in a comprehensive keynote paper. In addition to the formation of new grain boundaries, machining also leads to a significant increase in the dislocation density below the surface. These alternations in the microstructure contribute to strain hardening and result in an increase in microhardness as demonstrated by Outeiro et al. (2015) and Zhang et al. (2018a). Jawahir et al. (2016) concluded in a more recent keynote paper that the use of cryogenic cooling leads to a more pronounced grain refinement and thus stronger strain hardening compared with dry machining or machining with conventional flood cooling lubrication, due to the lower temperatures during machining.

Metastable austenitic steels are widely used in industry due to their favorable combination of strength and ductility as well as their excellent corrosion resistance. When cryogenically turning these steels, a deformation-induced phase transformation from the metastable $\gamma$-austenite into $\varepsilon$ - and $\alpha^{\prime}$-martensite can occur, which was first reported by Aurich et al. (2014). As the microhardness of the martensitic phase fractions is higher than the microhardness of the initially existent $\gamma$-austenite, this deformation-induced phase transformation contributes to the hardening of the surface layer. According to Pranke et al. (2015), the microhardness increases linearly with the phase fraction of martensite. Zhang et al. (2018b) demonstrated that the increase in microhardness caused by phase transformation as well as the microhardness increase caused by strain hardening superimpose additively. Due to this superposition of different hardening mechanisms, a pronounced surface hardening can be achieved by cryogenic turning of metastable austenitic steels. Depending on the application and the required surface integrity of the component, a separate hardening process can thus be rendered obsolete, leading to a more economical and ecological process chain. Frölich et al. (2015) proved that metastable austenitic steel AISI 347 showed a higher wear resistance after cryogenic turning compared to a conventional turning process in a radial shaft seal ring system. Boemke et al. (2018) showed that cryogenic turning leads to improved fatigue strength in the very high cycle fatigue regime, which was mainly contributed to the $\alpha^{\prime}$-martensite in the workpiece surface layer.

The understanding and quantification of the causal correlations between the input parameters, the thermomechanical load and the surface integrity, especially regarding the $\alpha^{\prime}$-martensite content, is of high technological and economic importance in order to tailor the cryogenic turning process depending on specific application requirements. The effects of the input parameters on the thermomechanical load and the resulting surface integrity are partly well understood: Mayer et al. (2018) reported on the influence of the cutting parameters, while the research of Hotz and Kirsch (2020) addressed the impact of the tool properties on the thermomechanical load and the surface integrity. These investigations demonstrate that, due to the deformation-induced phase transformation and strain hardening, the microhardness of the workpiece subsurface can almost be doubled by cryogenic turning. However, the correlation between the thermomechanical load and the deformation-induced phase transformation are not fully understood yet. While the past research implied that increasing mechanical loads and decreasing thermal loads benefit the deformation-induced phase transformation, which matches well with literature from materials science as we will discuss later, the exact correlations are not known. The existing phenomenological cause-effect relationships already allow the targeted configuration of the $\alpha^{\prime}$-martensite content in the workpiece surface layer by adjusting the input parameters. However, as the correlation of thermomechanical load and $\alpha^{\prime}$-martensite cannot be quantified yet, it is not possible to use a soft-sensor based approach for the in-situ estimation of the $\alpha^{\prime}$-martensite content. Hence it is also not possible to use a control loop in order to compensate disturbance variables, which is needed for a robust manufacturing of components with specific, predefined surface integrity.

In this article the impact of the thermomechanical load on deformation-induced phase transformation in the workpiece surface layer during cryogenic machining will be modeled for the first time. The parallel investigation of a parametric and a non-parametric modelling approach provides in-depth insights into the subsurface phase transformations during this machining process. The results will allow for the future implementation of a soft-sensor based process control and will also lead to an in-depth understanding of the cryogenic turning process.

\section{Fundamentals}

\section{Metastability from a thermodynamic point of view}

Metastable austenitic steels are characterized by the fact that compared to the initial $\gamma$-austenite microstructure a more energetically favorable state can be achieved by providing a critical amount of free energy $\Delta \mathrm{G}_{\text {min }}$. When cooling the material down to the martensite start temperature $\mathrm{M}_{\mathrm{s}}$, the martensitic phase transformation occurs. For this thermallyinduced phase transformation, the critical amount of free energy is solely provided by the temperature decrease. Patel 
and Cohen (1953) investigated the influence of applied stress on the martensitic phase transformation. With increasing stress, the mechanically induced free energy $\Delta \mathrm{G}_{\text {mech }}$ also increases, so that less thermal free energy $\Delta \mathrm{G}_{\text {therm }}$ has to be induced in order to reach the critical amount of free energy $\Delta \mathrm{G}_{\mathrm{min}}$. Hence, the phase transformation can occur at higher temperatures. This is illustrated schematically in Fig. 1a, based on a diagram by Vöhringer and Macherauch (1977). In Fig. 1b, which goes back to Olson and Cohen (1972), several cases of martensitic transformation in metastable austenitic steels can be differentiated depending on the temperature. As already mentioned, below the $\mathrm{M}_{\mathrm{s}}$-temperature, a solely thermally-induced phase transformation occurs. In the temperature range $\mathrm{M}_{\mathrm{s}} \leq \mathrm{T} \leq \mathrm{M}_{\mathrm{d}}$ a distinction can be made between stress-induced and deformation-induced martensite formation. In stress-induced martensite formation, an applied stress below the yield strength is sufficient to achieve $\Delta \mathrm{G}_{\text {mech }}$ at a given temperature. The temperature up to which stress-induced martensite formation occurs due to purely elastic deformation is referred to as $\mathrm{M}_{\mathrm{s}, \sigma}$, which was introduced by Bolling and Richman (1970). Above $M_{s, \sigma}$
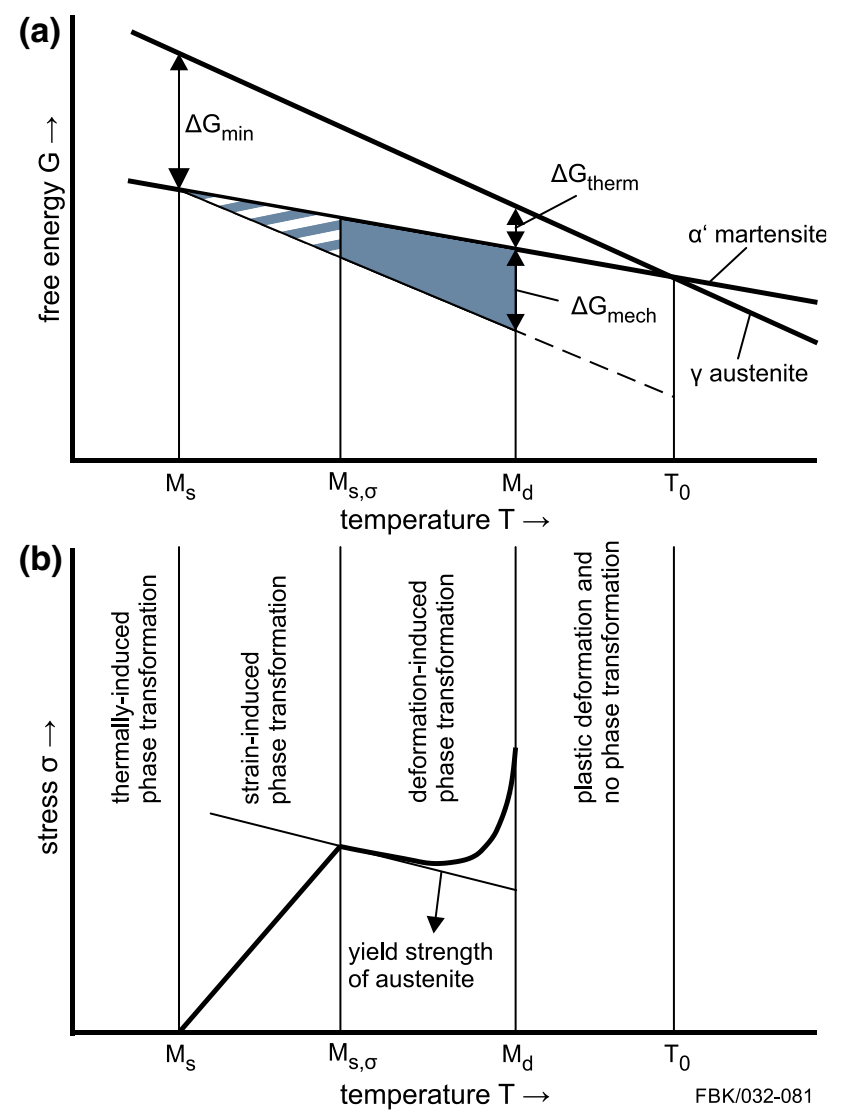

Fig. 1 a Schematic illustration of the free energy required for phase transformation depending on the temperature according to Vöhringer and Macherauch (1977), b applied stress necessary for martensitic phase transformation depending on the temperature according to Olson and Cohen (1972) the applied stress must surpass the yield strength to trigger the phase transformation. The deformation-induced martensite formation is characterized by plastic deformation. The martensite deformation temperature $\mathrm{M}_{\mathrm{d}}$ is the highest temperature at which the martensitic phase transformation can take place. Between $\mathrm{M}_{\mathrm{d}}$ and $\mathrm{T}_{0}$ the free energy of the $\alpha^{\prime}$-martensite is still below that of the $\gamma$-austenite, so that the phase transformation would still be possible from purely thermodynamic points of view (see Fig. 1a). However, the required critical free energy $\Delta \mathrm{G}_{\min }$ can no longer be applied, since the stress required to reach $\Delta \mathrm{G}_{\text {mech }}$ increases exponentially (see Fig. 1b).

The susceptibility of a metastable austenitic steel regarding martensitic phase transformation is not only determined by the applied thermomechanical load, but also by materialspecific properties, especially the chemical composition, which also highly influence the stacking fault energy, as discussed by Rhodes and Thompson (1977). The $\mathbf{M}_{\mathrm{s}}$ - and $\mathrm{M}_{\mathrm{d}}$-temperature can therefore be used as parameters for characterizing the material-specific austenite stability (see Fig. 1a). The first investigations in this regard go back to Eichelmann and Hull (1953), who empirically determined Eq. 1 in order to calculate the $\mathrm{M}_{\mathrm{s}}$-temperature of a steel as a function of its chemical composition. As it is hardly possible to experimentally determine the $\mathrm{M}_{\mathrm{d}}$-temperature, Angel (1954) introduced the $\mathrm{M}_{\mathrm{d} 30}$-temperature (see Eq. 2), at which $50 \% \alpha^{\prime}$ martensite is formed at $30 \%$ plastic deformation. The $\mathrm{M}_{\mathrm{s}}$-temperature can hence be used to evaluate the susceptibility regarding thermally-induced phase transformation (see Fig. 1a) and the $\mathrm{M}_{\mathrm{d} 30}$-temperature regarding deformation-induced phase transformation. In both cases, a higher temperature goes along with a higher susceptibility to phase transformation, or in other words, a lower austenite stability.

$\mathrm{M}_{\mathrm{s}}=1350-1665(\mathrm{C}+\mathrm{N})-28 \mathrm{Si}-33 \mathrm{Mn}-42 \mathrm{Cr}-61 \mathrm{Ni}$
$\mathrm{M}_{\mathrm{d} 30}=413-462(\mathrm{C}+\mathrm{N})-9.2 \mathrm{Si}-8.1 \mathrm{Mn}-13.7 \mathrm{Cr}-9.5 \mathrm{Ni}-18.5 \mathrm{Mo}$

\section{Nucleation and kinetics of deformation-induced phase transformation}

Herper (2000) summarized the characteristics of the martensitic transformation as a diffusion-free change of the lattice structure from face centered cubic (fcc) to body centered cubic (bcc), which is dominated by shearing, while the habitus plane remains unaffected. The nucleation of an $\alpha^{\prime}$-martensite embryo inside the fcc-lattice usually takes place at sites with high local distortion. Venables (1962) reported on the nucleation at the intersection of two plates of $\varepsilon$-martensite. Lagneborg (1964) stated that nucleation can also take place at intersections of active slip systems with 
$\varepsilon$-martensite plates. Furthermore, nucleation can also occur at the intersection of $\varepsilon$-martensite and a twin or grain boundary of the $\gamma$-austenite, as investigated by Mangonon and Thomas (1970). Besides the consecutive transformation of $\gamma$-austenite into $\varepsilon$-martensite and finally into $\alpha^{\prime}$-martensite, it is possible that $\alpha^{\prime}$-martensite is formed directly from $\gamma$-austenite, e.g. at the intersection of stacking faults, which was observed by Schumann (1975) and Staudhammer et al. (1983). Olson and Cohen (1975) summarized $\varepsilon$-martensite plates, twins and bundles of stacking faults with the term "shear bands", because their intersections all serve as nucleation sites for $\alpha^{\prime}$-martensite embryos and they are furthermore difficult to distinguish microscopically.

Pati and Cohen (1969) state that after nucleation of the first $\alpha^{\prime}$-martensite embryo an autocatalytic transformation occurs in the adjacent lattice, as the lattice structure is already disturbed and less free energy is needed for the phase transformation. This means that after nucleation the phase transformation rapidly spreads until the transformation front encounters an obstacle. Grain boundaries, for example, represent such obstacles, which is why increasing grain sizes favor the deformation-induced formation of $\alpha^{\prime}$-martensite, as elaborated by Nohara et al. (1977).

The kinetics of the deformation-induced phase transformation from $\gamma$-austenite to $\alpha^{\prime}$-martensite were firstly modeled by Olson and Cohen (1975). They found that the $\alpha^{\prime}$-martensite contents determined experimentally by Angel (1954) at constant temperature resulted in a sigmoidal function depending on the plastic strain. In their model, they regarded shear band intersections as the dominant nucleation sites, which increase with increasing plastic strain. The volume fraction of shear bands $\mathrm{f}^{\mathrm{sb}}$ increases with rising plastic strain $\varepsilon$ according to Eq. 3, while $\alpha$ is a strain-independent parameter representing the rate of shear band formation, which is sensitive to stacking fault energy and strain rate.

$\mathrm{f}^{\mathrm{sb}}=1-\mathrm{e}^{-\alpha \cdot \varepsilon}$

They assumed that a single shear band has a constant volume of $\mathrm{v}^{\mathrm{sb}}$, hence the number of shear bands per austenite volume $N_{v}^{s b}$ can be calculated with Eq. 4 .

$\mathrm{N}_{\mathrm{v}}^{\mathrm{sb}}=\frac{\mathrm{f}^{\mathrm{sb}}}{\mathrm{v}^{\mathrm{sb}}}$

The number of shear band intersections per austenite volume $\mathrm{N}_{\mathrm{v}}^{\mathrm{I}}$ was then related to the number of shear bands with Eq. 5 with a constant $\mathrm{K}$ and an exponent $\mathrm{n}$.

$\mathrm{N}_{\mathrm{v}}^{\mathrm{I}}=\mathrm{K} \cdot\left(\mathrm{N}_{\mathrm{v}}^{\mathrm{sb}}\right)^{\mathrm{n}}$

As not every shear band intersection leads to $\alpha^{\prime}$-martensite nucleation, they correlated the number of $\alpha^{\prime}$-martensite embryos $\mathrm{N}_{\mathrm{v}}^{\alpha^{\prime}}$ to the number of shear band intersections $\mathrm{N}_{\mathrm{v}}^{\mathrm{I}}$, whereby $\mathrm{p}$ was the probability for nucleation: $d \mathrm{~N}_{\mathrm{v}}^{\alpha^{\prime}}=\mathrm{p} \cdot d \mathrm{~N}_{\mathrm{v}}^{\mathrm{I}}$

The probability of nucleation $\mathrm{p}$ was expressed as a gaussian distribution function relative to the temperature. When using Eqs. 3-6, Eq. 7 can be derived to calculate the phase fraction of $\alpha^{\prime}$-martensite f $\alpha^{\prime}$ depending of the strain $\varepsilon$, the exponent $\mathrm{n}$ and two parameters $\alpha$ and $\beta$, which are sensitive to temperature, as $\alpha$ depends on the stacking fault energy and $\beta$ is proportional to the probability $\mathrm{p}$ of nucleation at a shear band intersection (see Eq. 8).

$\mathrm{f}^{\alpha^{\prime}}=1-\mathrm{e}^{-\beta \cdot\left(1-\mathrm{e}^{-\alpha \cdot \varepsilon}\right)^{\mathrm{n}}}$

$\beta=\frac{\mathrm{v}^{\alpha^{\prime}} \cdot \mathrm{K}}{\mathrm{v}^{\mathrm{sbn}}} \cdot \mathrm{p}$

When setting the exponent to $\mathrm{n}=4.5$, Olson and Cohen (1975) were able to fit the experimental data of Angel (1954) very well for a wide range of temperatures and plastic strains. The model attracted considerable attention in the scientific community and is still frequently used for calculations regarding the deformation-induced formation of $\alpha^{\prime}$ - martensite. Hecker et al. (1982) extended the model of Olson and Cohen (1975) for biaxial loading by substituting the uniaxial strain with the von Mises effective strain. They proved validity to the Olson-Cohen model. However, they needed to adapt the temperature sensitive parameters $\alpha$ and $\beta$. This is probably due to the fact that a different batch of metastable austenitic steel was used and the different chemical composition and thus different austenitic stability led to the deviations in metastability. Huang et al. (1989) provided an overview of the effect of plastic strain and temperature. Figure 2 shows the results of Angel (1954) in solid lines, the dotted lines represent extrapolation of Angels data by the model of Olson and Cohen (1975) and the dashed lines show the results obtained by Hecker et al. (1982). With increasing

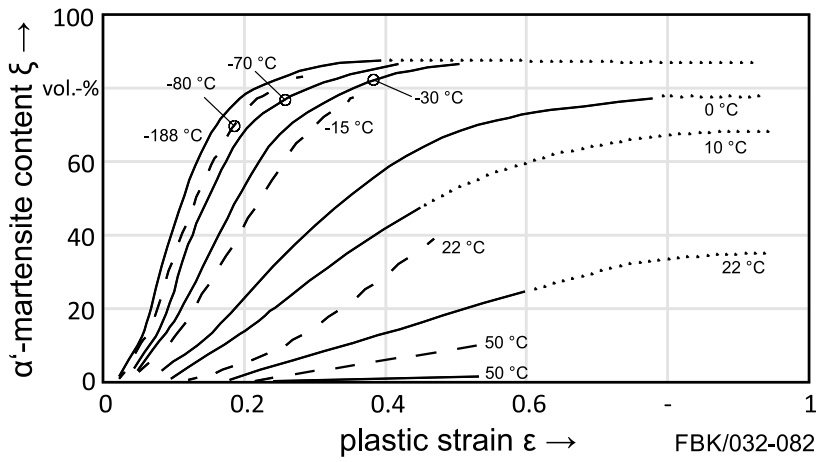

Fig. 2 Content of $\alpha^{\prime}$-martensite in metastable austenitic steel AISI 304 as a function of plastic strain at different temperatures according to Huang et al. (1989): solid lines by Angel (1954), dotted lines by Olson and Cohen (1975), dashed lines by Hecker et al. (1982) 
plastic strain, the sigmoid shaped functions lead to a saturation, at which further increasing the strain does not increase the $\alpha^{\prime}$-martensite content. The plateau depends on the temperature sensitive parameter $\beta$.

Inspired by the model of Olson and Cohen (1975), further approaches for modeling the deformation-induced $\alpha^{\prime}$-martensite formation by means of sigmoidal functions were developed by several researchers. Stringfellow et al. (1992) take the changes in the mechanical properties during phase transformation into account. Based on this, Zaera et al. (2012) developed a constitutive model for calculating the $\alpha^{\prime}$-martensite content at very high strain rates. Ahmedabadi et al. (2016) modeled the sigmoidal curve by means of a logistic function and found a good agreement with the model by Olson and Cohen (1975). Smaga et al. (2008) used a sigmoid function in order to calculate the amount of deformation induced $\alpha^{\prime}$-martensite in fatigue experiments. In their model, they used the cumulative plastic strain, which results from the number of cycles and the plastic strain of the individual cycles.

Das et al. (2011a) used ANN to investigate various impact factors on the deformation-induced formation of $\alpha^{\prime}$-martensite. They compared the influence of materialspecific properties such as chemical composition and grain size with the influence of thermomechanical load on the $\alpha^{\prime}$-martensite content. According to this study, the temperature has the greatest influence, closely followed by the applied stress. Interestingly, stress had a much greater effect on the phase transformation than strain. The strain rate had only a marginal influence. While using the experimental data of 26 publications in their ANN, Das et al. (2011b) proved that a large amount of published data regarding the $\alpha^{\prime}$-martensite content depending on the plastic strain can actually be described with the effect of stress. This conclusion matches well with the thermodynamic aspects of deformation induced phase transformation, as the stress contributes to the mechanically induced free energy $\Delta \mathrm{G}_{\text {mech }}$ (see Fig. 1). Das et al. (2011a,b) show that the $\alpha^{\prime}$-martensite content increases in a sigmoidal function depending on the stress, whereby a critical minimum stress must be applied to overcome the yield stress and to realize plastic deformation. Similar correlations between the stress and the $\alpha^{\prime}$-martensite content were more recently obtained by Ishimaru et al. (2015) in cyclic tension-compression tests and also after draw bending of metastable austenitic steel.

\section{Methodology and experimental procedure}

\section{Modelling approach}

Compared to material science investigations regarding the influence of thermomechanical load on the deformation-induced formation of $\alpha^{\prime}$-martensite, several particularities have to be taken into account for cryogenic turning which make the modelling more difficult. First, stress, strain and temperature are not the adjustment parameters of the experiment, but result depending on the choice of the cutting parameters, the cooling strategy and the tool properties, which represent the input parameters during cryogenic turning. Therefore, in the experiments, the thermomechanical load must be modified by a variation of these input parameters, which requires a priori knowledge. Second, during the experiments, the stress, strain and temperature are not homogeneously distributed inside the workpiece material and therefore the resulting $\alpha^{\prime}$-martensite content is not homogeneously distributed either, unlike for instance in unidirectional tensile or fatigue tests. The $\alpha^{\prime}$-martensite is locally generated when the tool causes a mechanical load in the subsurface at a temperature given at that point in time. Depending on the distance from the surface, there are steep gradients in stress, strain, temperature and $\alpha^{\prime}$-martensite content. Third, the characterization of thermomechanical loads in the workpiece subsurface during the cryogenic turning is rather difficult. The equivalent stress within the subsurface can be calculated e.g. according to a model developed by Garbrecht (2006). However, the equivalent stress depends not only on the forces but also directly on the contact conditions, which means on the tool design. The plastic strain in the subsurface caused by turning can be examined ex-situ by analyzing the microstructure by means of electron back scatter diffraction or metallographic examinations. Furthermore, the elastic and plastic strain can also be modeled as a function of the equivalent stress if a material model is used in which the stress strain response takes the deformationinduced martensite formation and the associated changes in mechanical behavior into account. The temperature in the area of the inaccessible contact zone can hardly be measured. Becker et al. (2018) developed a model which allows for the calculation of the temperature distribution inside the workpiece during cryogenic turning. However, numerical errors occur in an area up to approx. $200 \mu \mathrm{m}$ below the surface. This leads to unreliable predictions for the temperature in the area in which the deformation-induced phase transformation occurs.

Due to the difficulties in determining the thermomechanical load as a function of the distance to the surface, it is advisable to model the mean $\alpha^{\prime}$-martensite content in the workpiece subsurface which requires input variables that are not location-dependent and therefore easier to determine. As mentioned, according to Das et al. (2011a,b), the stress has a significantly higher impact on deformation-induced $\alpha^{\prime}$-martensite formation than the strain. Thus, when considering the mechanical load, the process forces, which are very easy to measure, were used as input variables. As the input variable regarding the thermal load the temperature, 


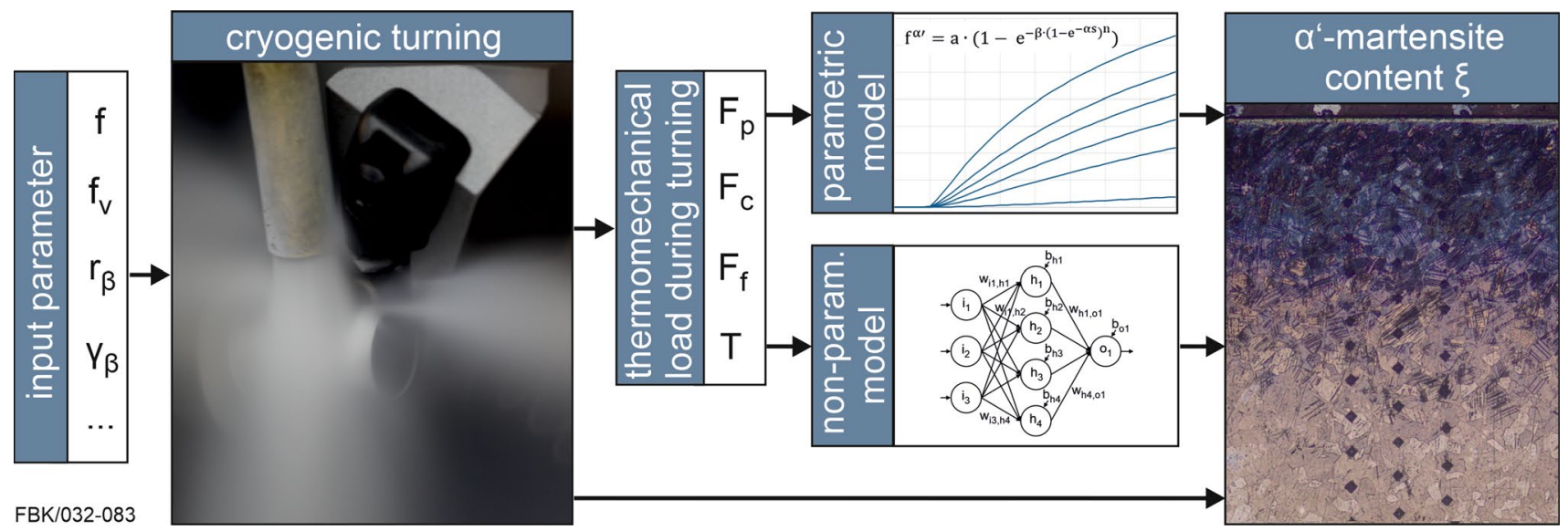

Fig. 3 Schematic illustration of the modelling approach

Table 1 Chemical composition of metastable austenitic steel AISI 347 in wt $\%$

\begin{tabular}{llllllllll}
\hline $\mathrm{C}$ & $\mathrm{Cr}$ & $\mathrm{Ni}$ & $\mathrm{N}$ & $\mathrm{Nb}$ & $\mathrm{Mn}$ & $\mathrm{Mo}$ & $\mathrm{Si}$ & $\mathrm{Cu}$ & $\mathrm{Fe}$ \\
\hline 0.021 & 17.19 & 9.44 & 0.022 & 0.38 & 1.55 & 0.23 & 0.59 & 0.11 & Rest \\
\hline
\end{tabular}

measured inside the workpiece near the surface, was used, which will be described later in greater detail. The $\alpha^{\prime}$-martensite content was measured ex-situ with a magnetic sensor. The integral value determined in this way represents the target variable according to which the models were fitted to. As schematically illustrated in Fig. 3, two different models have been developed to calculate the $\alpha^{\prime}$-martensite content in the workpiece subsurface as a function of the process forces and the temperature. On the one hand, a parametric model was developed based on the fundamentals of deformation-induced phase transformation (see Sect. 2). On the other hand, a non-parametric model was developed using ANN. The same 51 data sets (process forces, temperature, $\alpha^{\prime}$-martensite content) were used for the development of both models. Data sets of four experiments which were not included in the development of the models were then used for testing.

\section{Workpiece material}

Metastable austenitic stainless steel AISI 347 was used for the investigations. Because varying chemical composition and thus varying austenite stability have an influence on the deformation-induced phase transformation during cryogenic turning, as discussed by Kirsch et al. (2019), the same batch was used for all experiments. Based on the chemical composition (see Table 1) the $\mathrm{M}_{\mathrm{s}}$-temperature can be calculated to $-87^{\circ} \mathrm{C}$, according to Eq. 1 . The $\mathrm{M}_{\mathrm{d} 30}$-temperature amounts to $46^{\circ} \mathrm{C}$, according to Eq. 2. The average grain diameter of the initial austenitic microstructure was $17 \mu \mathrm{m}$ and the initial microhardness was 187 HV0.01.

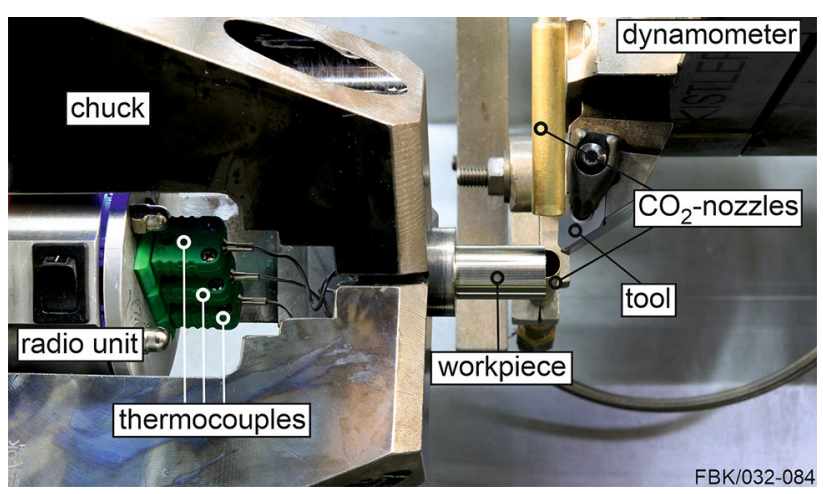

Fig. 4 Experimental setup

\section{Machining setup}

The longitudinal turning experiments were carried out on a CNC lathe (see Fig. 4). The feed travel was $18 \mathrm{~mm}$ at a final workpiece diameter of $14 \mathrm{~mm}$. A bi-phase $\mathrm{CO}_{2}$ solid-gas mixture was used for cooling. The $\mathrm{CO}_{2}$ was supplied via two nozzles with a constant mass flow rate of $1.75 \mathrm{~kg} /$ min per nozzle. A depth of cut of $a_{p}=0.2 \mathrm{~mm}$ and a cutting speed of $v_{c}=30 \mathrm{~m} / \mathrm{min}$ were used. The feed rate was varied in a wide range in order to cause variations in the thermomechanical load during turning. Furthermore, the tool properties were varied: 5 different coatings as well as uncoated inserts were used. The cutting edge radius $r_{\beta}$, the form factor $K$ of the cutting edge and the chamfer angle $\gamma_{\beta}$ were varied as well. At several experiments, a precooling was applied in order to manipulate the thermal load. During 
precooling, the tool moved slightly above the workpiece with activated cooling without removing a chip. While the $\mathrm{CO}_{2}$-mass flow was constant, the feed rate during precooling $\left(f_{p c}\right)$ was varied in order to adjust the workpiece temperature immediately before machining. All these variations of the input parameter aimed at varying the thermomechanical load during cryogenic turning in order to analyze and model the influence between thermomechanical load and the extent of deformation-induced $\alpha^{\prime}$-martensite formation. An overview of the used parameters, the measured process forces and temperatures, the resulting $\alpha^{\prime}$-martensite contents as well as the modeled $\alpha^{\prime}$-martensite contents is given in the "Appendix".

\section{Measurement technology}

During the cryogenic turning, a three-component peizoelectric dynomometer was used to measure the cutting force $F_{c}$, the passive force $F_{p}$ and the feed force $F_{f}$. In order to measure the temperature within the workpiece subsurface, type $\mathrm{K}$ thermocouples $(\mathrm{NiCr}-\mathrm{Ni})$ with a diameter of $1 \mathrm{~mm}$ were used. They were positioned in eroded holes with a diameter of $1.2 \mathrm{~mm}$. Before insertion, the holes were filled with a heat transfer compound to ensure good heat transfer between the thermocouples and the borehole wall. The distance between the centre of the the thermocouple and the workpiece surface after machining (diameter $14 \mathrm{~mm}$ ) was $1 \mathrm{~mm}$. The thermocouples were connected to a radio unit positioned between the clamping chucks (see Fig. 4). This enabled to transmit the measuring signals to a receiver outside the $\mathrm{CNC}$ lathe. The time synchronous recording of the process forces and the temperatures made it possible to evaluate the temperatures as a function of the cutting time. In axial direction, the tool surpassed the thermocouples after machining a feed travel of $10 \mathrm{~mm}$. The heat generated by machining conducted into the workpiece subsurface and resulted in a temperature increase. The temperature $\mathrm{T}$ of the local maximum was dependent on the input parameters. This maximum temperature was used as the input variable for model development, as it represents the temperature within the workpiece subsurface during machining.

The deformation-induced phase transformation occuring during cryogenic turning led to changes in permeability, which were measured by means of the magnetic sensor Feritscope FMP $30^{1}$ subsequent to the turning experiments. While this does not allow to measure the content of the paramagnetic $\varepsilon$-martensite and also does not yield any information regarding the $\alpha^{\prime}$-martensite, this is still a reliable method to determine the $\alpha^{\prime}$-martensite content of a workpiece fast and non-destructively immediately after cryogenic turning. For each workpiece, the $\alpha^{\prime}$-martensite content was measured at eight equidistant points in circumferential direction and five points in axial direction, so that the measurement grid covered the whole area of the machined workpiece surface. The mean value of the total 40 measurement points was calculated in order to give a representative $\alpha^{\prime}$-martensite content of a single workpiece. While the field lines of the magnetic sensor flow through the component up to a depth of approx. 3-4 mm, the $\alpha^{\prime}$-martensite content after the cryogenic turning is usually located within the first $200 \mu \mathrm{m}$ below the surface. Therefore the measurement signals determined by the magnetic sensor were always significantly lower than the actual $\alpha^{\prime}$-martensite content in the near surface layer. For calibration, cross sections of the cryogenically turned workpieces were treated with Beraha II etching agent in order contrast the $\alpha^{\prime}$-martensite needles. In addition to workpieces that were cryogenically turned within the framework of this study, workpieces with exceptionally high and low $\alpha^{\prime}$-martensite content from earlier studies by Mayer et al. (2018) and Hotz et al. (2018) were also used for calibration. After capturing images with an optical microscope, an image processing method according to Mayer et al. (2018) was used in order to quantify the $\alpha^{\prime}$-martensite content in the surface layer and give insights into the $\alpha^{\prime}$-martensite distribution. The $\alpha^{\prime}$-martensite content $\xi_{\mathrm{m}}$ deterimed with the magnetic sensor was then compared to the mean $\alpha^{\prime}$-martensite phase fraction $f \alpha^{\prime}$ within the workpiece subsurface. The resulting calibration curve given in Fig. 5 is a superposition of a root function and a linear function (see Eq. 9) and is qualitatively in good agreement with an overview given by Talonen et al. (2004), who compared the Feritscope ${ }^{1}$ calibration curves when measuring the $\alpha^{\prime}$-martensite content of different researchers including Hecker et al. (1982).

$\mathrm{f}^{\alpha^{\prime}}=5.86 \cdot \sqrt{\xi_{\mathrm{m}}}+1.17 \cdot \xi_{\mathrm{m}}$

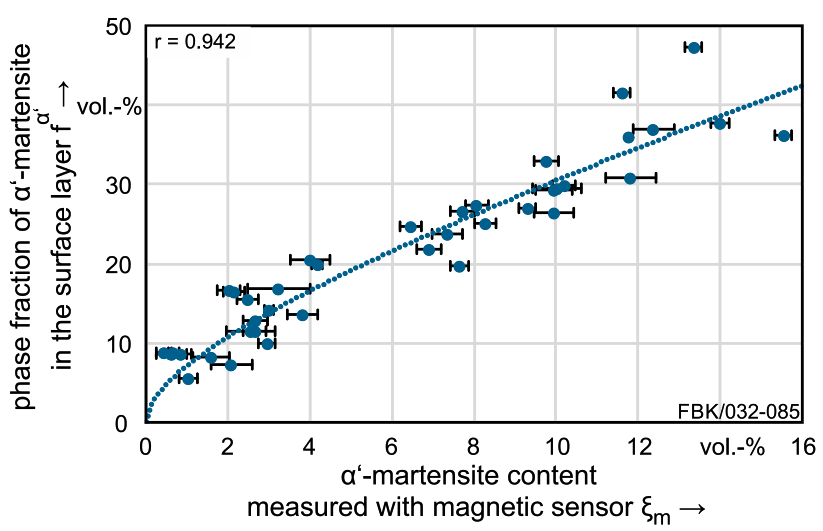

Fig. 5 Calibration curve of magnetic sensor 


\section{Results}

\section{Experimental results}

The wide range of varied input parameters in cryogenic turning led to a great data range of process forces, temperatures and consequently the resulting $\alpha^{\prime}$-martensite content. Figure 6 provides an overview on the influence of thermomechanical load on the $\alpha^{\prime}$-martensite content $\xi_{\mathrm{m}}$ measured with the magnetic sensor, each accompanied by the trend line, the 95\% confidence interval and the correlation coefficient $r$.

It can be seen, that the $\alpha^{\prime}$-martensite content increased with higher cutting force $\mathrm{F}_{\mathrm{c}}$ and passive force $\mathrm{F}_{\mathrm{p}}$. The similar influence of cutting force and passive force can be explained by the fact that these themselves correlate strongly with each other $(r=0.89)$. The feed force did not have a significant influence on the deformation-induced phase transformation. As expected, rising temperatures inhibited the phase transformation. Due to the conversion of mechanical energy into heat in the nearly adiabatic primary shear zone, a high negative correlation between cutting force and temperature could be expected, which would make it difficult to separate the individual influences on $\alpha^{\prime}$-martensite formation. However, due to the modification of the temperature by means of varying precooling, the correlation between the process forces and the temperatures is very low (see Table 2).

Although trends can be seen regarding the influence of cutting force, passive force and temperature on deformation-induced phase transformation, the overall scatter is very high. This is because the deformation-induced formation of $\alpha^{\prime}$-martensite cannot be explained solely by the mechanical or thermal load, but only by their superposition.

Table 2 Correlation coefficients between the different measured values

\begin{tabular}{llllll}
\hline- & $\mathrm{F}_{\mathrm{c}}$ & $\mathrm{F}_{\mathrm{p}}$ & $\mathrm{F}_{\mathrm{f}}$ & $\mathrm{T}$ & $\xi_{\mathrm{m}}$ \\
\hline $\mathrm{F}_{\mathrm{c}}$ & 1 & 0.89 & 0.618 & -0.173 & 0.68 \\
$\mathrm{~F}_{\mathrm{p}}$ & 0.89 & 1 & 0.382 & -0.058 & 0.727 \\
$\mathrm{~F}_{\mathrm{f}}$ & 0.618 & 0.382 & 1 & 0.193 & 0.108 \\
$\mathrm{~T}$ & -0.173 & -0.058 & 0.193 & 1 & -0.628 \\
$\xi_{\mathrm{m}}$ & 0.68 & 0.727 & 0.108 & -0.628 & 1 \\
\hline
\end{tabular}
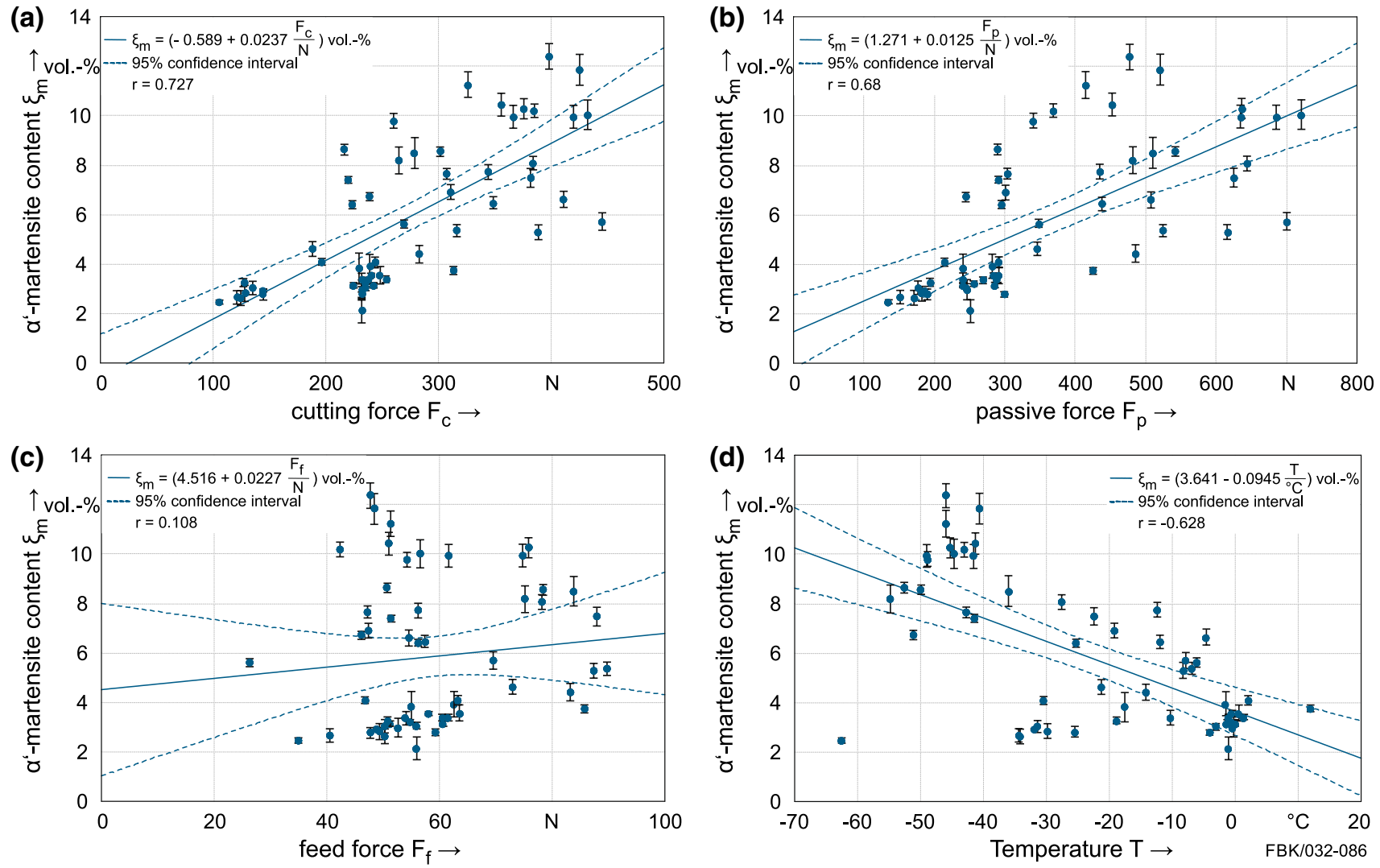

Fig. $6 \alpha^{\prime}$-martensite content depending on $\mathbf{a}$ the cutting force, $\mathbf{b}$ the passive force, $\mathbf{c}$ the feed force and $\mathbf{d}$ the temperature 


\section{Parametric model}

Based on the fundamentals regarding the deformationinduced phase transformation (see Sect. 2), it seems reasonable to use a sigmoidal function in order to model the impact of the thermomechanical load during cryogenic turning on the $\alpha^{\prime}$-martensite content. Therefore, the approach we have chosen (Eq. 10) is based on the model given by Olson and Cohen (1975) in Eq. 7.

$\mathrm{f}^{\alpha^{\prime}}=\mathrm{a} \cdot\left(1-\mathrm{e}^{-\beta \cdot\left(1-\mathrm{e}^{-\alpha \varsigma}\right)^{\mathrm{n}}}\right)$

As already discussed, the applied stress generally has a higher influence on the deformation-induced formation of $\alpha^{\prime}$-martensite than strain and is much easier to determine during cryogenic turning. Therefore, we replaced the strain $\varepsilon$ in Eq. 7 with a substitution term s, which depends on the measured process forces. The fitting parameter a takes into account the inhomogeneous $\alpha^{\prime}$-martensite distribution in the workpiece surface. The best possible fitting results were achieved with a value of $a=0.67$, which was kept constant for all calculations. Like Olson and Cohen (1975) as well as Hecker et al. (1982) we used a constant exponent of $n=4.5$, which led to a good agreement between the experiment and model.

The parameter $\alpha$ and $\beta$, which are also used in the OlsonCohen model (Eq. 7), provide temperature sensitivity to the model as these parameters reflect the rate of shear band formation $(\alpha)$ and the temperature depended probability of nucleation at a shear band intersection ( $\beta$ ). For $\alpha$ and $\beta$ data from literature was used: In direct comparison, the parameter obtained by Hecker et al. (1982) led to better results than the parameter determined by Olson and Cohen (1975) based on the data of Angel (1954). Thus, based on the data given by Hecker et al. (1982), the following temperature depend equations were used in Eq. 10.

$$
\begin{aligned}
& \alpha=5 \cdot 10^{-9} \cdot \mathrm{T}^{4}+5 \cdot 10^{-7} \cdot \mathrm{T}^{3}-2 \cdot 10^{-4} \cdot \mathrm{T}^{2} \\
& \quad-0.0735 \cdot \mathrm{T}+7.0079
\end{aligned}
$$

$\beta=2.1-\left(\frac{2.3}{1.093+\mathrm{e}^{(2.35-0.1 \cdot \mathrm{T})}}\right)$

Different possibilities to appropriately include the mechanical load in the model were investigated. The best approximations were achieved when only the data of the cutting force $F_{c}$ was used. Including the passive force $F_{p}$ and especially the feed force $F_{f}$ led to worse estimates. Equation 13 containing three fitting parameters $b, c$ and $d$ was used to calculate the substitution term s, which represents the strain $\varepsilon$ in the Olson-Cohen model (Eq. 7).

The parameter $b$ takes into account that a certain threshold must be overcome in order for plastic deformation and ultimately deformation-induced phase transformation to occur. This parameter was fitted to $b=92 \mathrm{~N}$ and kept constant for all calculations. An increase in $\mathrm{F}_{\mathrm{c}}$ leads to a degressive increase of $\mathrm{s}$, which was considered by the constant exponent $\mathrm{c}=0.235$. The parameter $\mathrm{d}$ was adjusted to $\mathrm{d}=6.5 \cdot 10^{5}$ to fit the overall magnitude of $\mathrm{s}$, and hence the significance of the mechanical load in comparison to the thermal load.

$\mathrm{s}=\left(\frac{\mathrm{F}_{\mathrm{c}}-\mathrm{b}}{\mathrm{d}}\right)^{\mathrm{c}}$

The martensitic phase fraction $\mathrm{f}^{\prime}$ calculated with Eq. 10 was converted to the integral value using the inverse function of the calibration curve (Eq. 14). Thus, the $\alpha^{\prime}$-martensite contents $\xi_{\mathrm{c}, \mathrm{p}}$ calculated using a parametric model could be compared with the actually measured $\alpha^{\prime}$-martensite contents $\xi_{\mathrm{m}}$. This comparison is shown in Fig. 7 to evaluate the model performance.

$\xi_{c, p}=\mathrm{f}^{\alpha^{\prime}}-2.305 \cdot \sqrt{\mathrm{f}^{\alpha^{\prime}}+85}+21.25$

The proposed model, which combines the influences of the thermal and the mechanical load, led to a much higher correlation $(r=0.955)$ than the single influence of the process forces or the temperature (see Fig. 6). However, in some cases there are larger deviations, which are particularly noticeable in the case of low $\alpha^{\prime}$-martensite contents. Furthermore, the trend line does not exactly intersect the origin and rises too steeply, resulting in a general underestimation of low $\alpha^{\prime}$-martensite values and an overestimation of high $\alpha^{\prime}$-martensite values. Nevertheless, as implied by the $95 \%$ confidence interval, this model allows a decent estimation of the resulting $\alpha^{\prime}$-martensite content depending on the process forces and temperatures monitored during cryogenic turning. An increase of the exponent $n$ would prevent the

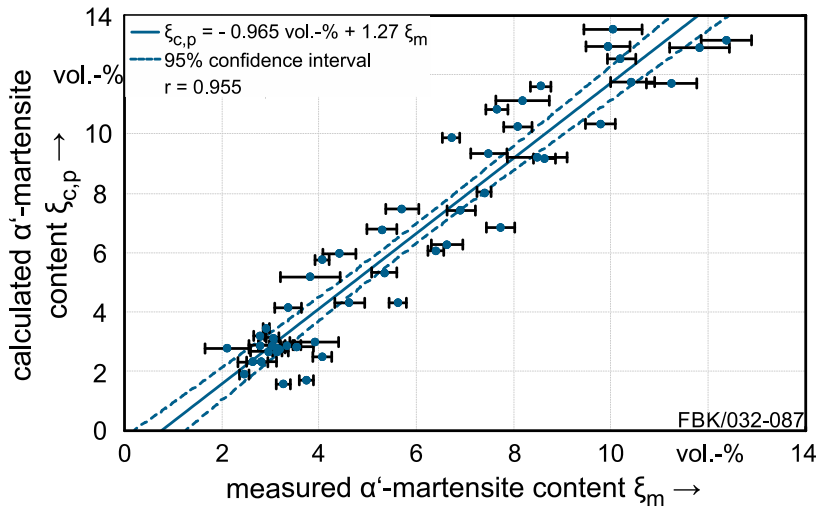

Fig. 7 Comparison of measured $\alpha^{\prime}$-martensite content $\xi_{\mathrm{m}}$ and $\alpha^{\prime}$-martensite content calculated with the parametric model $\xi_{\mathrm{c}, \mathrm{p}}$ 
overestimation of high $\alpha^{\prime}$-martensite values because saturation occurs already at lower cutting forces. However, this would lead to an even more pronounced underestimation of the low $\alpha^{\prime}$-martensite values. Thus, a variation of the exponent $\mathrm{n}$ cannot significantly improve the performance of the parametric model.

\section{Non-parametric model}

The multilayer perceptron with three layers (MLP 3-4-1) was the chosen architecture for the ANN used in this study (see Fig. 8). The input layer had three neurons, one for the cutting force $F_{c}$, one for the passive force $F_{p}$ and one for the temperature $\mathrm{T}$. It became apparent that the model performance deteriorated when adding the feed force $F_{f}$ as a fourth input neuron, which is why the feed force was not included in the ANN. The output layer was defined by only one neuron for the martensite content, in which the measurement data of the magnetic sensor were used as the target. A number of four neurons in the hidden layer led to the best model performance.

The value of a specific neuron $h_{m}$ in the hidden layer was determined by the activation function of the sum of multiplication of the value of the neurons of the input layer $\left(i_{1}, i_{2}\right.$ and $\left.\mathrm{i}_{3}\right)$ and their corresponding weight functions $\left(\mathrm{w}_{\mathrm{i} 1, \mathrm{hm}}, \mathrm{w}_{\mathrm{i} 2, \mathrm{hm}}\right.$ and $\mathrm{w}_{\mathrm{i} 3, \mathrm{hm}}$ ) plus the neurons $\mathrm{h}_{\mathrm{m}}$ designated bias $\mathrm{b}_{\mathrm{hm}}$. ANN with different activation functions were trained: hyperbolic tangent (Eq. 15), identity (Eq. 16), exponential (Eq. 17) and logistic sigmoid (Eq. 18). With the same types of functions, the value of the single neuron $\mathrm{o}_{1}$ in the output layer was also calculated.

$\mathrm{h}_{\mathrm{m}}=\tanh \left(\sum_{\mathrm{n}}^{3}\left(\mathrm{w}_{\mathrm{in}, \mathrm{hm}} \cdot \mathrm{i}_{\mathrm{n}}+\mathrm{b}_{\mathrm{hm}}\right)\right)$

$\mathrm{h}_{\mathrm{m}}=\sum_{\mathrm{n}}^{3}\left(\mathrm{w}_{\mathrm{in}, \mathrm{hm}} \cdot \mathrm{i}_{\mathrm{n}}+\mathrm{b}_{\mathrm{hm}}\right)$

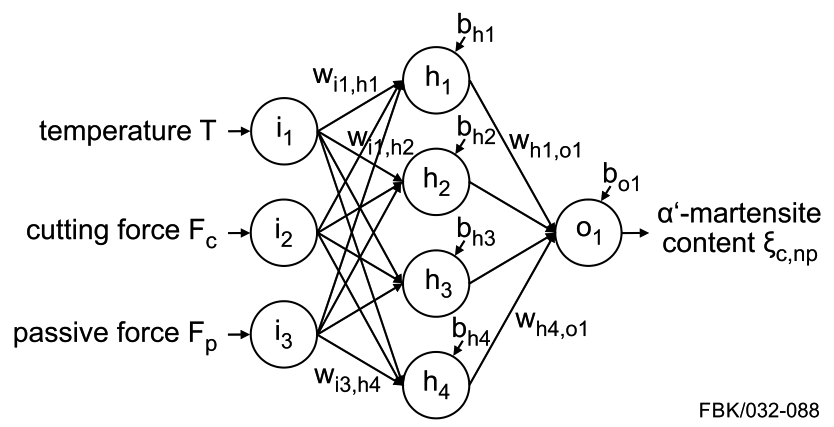

Fig. 8 Architecture of artificial neural network $\mathrm{h}_{\mathrm{m}}=\mathrm{e}^{\sum_{\mathrm{n}}^{3}\left(\mathrm{w}_{\mathrm{in}, \mathrm{hm}} \cdot \mathrm{i}_{\mathrm{n}}+\mathrm{b}_{\mathrm{hm}}\right)}$

$\mathrm{h}_{\mathrm{m}}=\frac{1}{1+\mathrm{e}^{\sum_{\mathrm{n}}^{3}\left(\mathrm{w}_{\mathrm{in}, \mathrm{hm}} \cdot \mathrm{i}_{\mathrm{n}}+\mathrm{b}_{\mathrm{hm}}\right)}}$

Out of the 55 data sets for cutting force, passive force, temperature and $\alpha^{\prime}$-martensite content, 44 were used for training, 7 for validation and 4 for testing. BroydenFletcher-Goldfarb-Shanno (BFGS) was used as the training algorithm (Broyden, 1970; Fletcher 1970; Goldfarb 1970; Shanno 1970). In order to quantify the differences between the model predictions $o_{1}$ and the measured $\alpha^{\prime}$-martensite content $\xi_{\mathrm{m}}$, during training, the sum of squares was used as an error function (Eq. 19, $\mathrm{n}$ represents the number of data sets). The same equation was used to calculate the validation error $\mathrm{E}_{\mathrm{val}}$ with the validation data sets.

$\mathrm{E}=\sum_{\mathrm{i}}^{\mathrm{n}}\left(\mathrm{o}_{1, \mathrm{i}}-\xi_{\mathrm{m}, \mathrm{i}}\right)^{2}$

According to the BFGS-algorithm, large sum of square errors $E_{\text {train }}$ in the training data set will lead to great weight adjustment in the subsequent training cycle et vice versa. The validation data sets were used for implementing an early stopping routine in order to avoid overfitting of the training data. As long as the validation error $\mathrm{E}_{\mathrm{val}}$ decreases during the training process, the performance of the model did improve, but when it increased, overfitting was identified and the training process was ended.

A total of 100 ANN were trained, of which the 10 with the lowest error were used for further analysis. In these 10 ANN, between 29 and 191 training cycles were performed until early stopping was triggered. No significant difference between the activation functions and the performance was observed. An overview of the used activation functions, the number of epochs during training as well as the weights and biases is given in the "Appendix".

The $\alpha^{\prime}$-martensite content $\xi_{\mathrm{c}, \text { np }}$ of a single workpiece was then determined by calculating the mean value of the output neuron $o_{1}$ of the 10 best ANN. The $\alpha^{\prime}$-martensite contents $\xi_{\mathrm{c}, \mathrm{np}}$ thus calculated are plotted in Fig. 9 in comparison to the measurement data $\xi_{\mathrm{m}}$. The calculated values match the measurement data very well which can be quantified by the high correlation coefficient of $r=0.987$. Besides the higher correlation coefficient, there was no systematic under- or overestimation, as it was the case in the parametric model (see Fig. 7), which can be seen considering the almost ideal course of the trend line and the confidence interval around it.

A global sensitivity analysis was carried out in order to quantify the importance of the three different input variables. Repeatedly, each input variable in turn was replaced by its mean value from the training sample. The sensitivity 


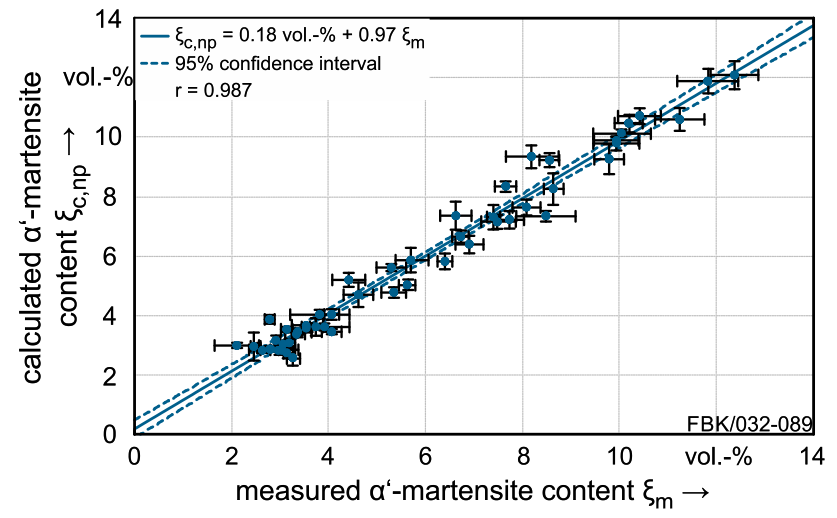

Fig. 9 Comparison of measured $\alpha^{\prime}$-martensite content $\xi_{\mathrm{m}}$ and $\alpha^{\prime}$-martensite content calculated with the non-parametric model $\xi_{\mathrm{c}, \mathrm{np}}$

Table 3 Sensitivity indices of the input variables

\begin{tabular}{lrrr}
\hline & \multicolumn{1}{l}{$\mathrm{T}$} & \multicolumn{1}{c}{$\mathrm{F}_{\mathrm{c}}$} & \multicolumn{1}{c}{$\mathrm{F}_{\mathrm{p}}$} \\
\hline $\mathrm{S}_{\min }$ & 11.61 & 10.88 & 4.39 \\
$\mathrm{~S}_{\text {max }}$ & 14.99 & 41.81 & 11.07 \\
$\mathrm{~S}_{\text {mean }}$ & 13.61 & 15.49 & 6.84 \\
$\sigma_{\mathrm{S}}$ & 1.15 & 9.43 & 1.93 \\
\hline
\end{tabular}

index S quantifying the network error can be used as evaluation criterion, where high indices corresponds to a high significance of the modified input variable. A sensitivity index of less than 1 would indicate that the input variable is clearly insignificant to the output variable and the model performance would undoubtedly be superior without it. The minimum $\left(\mathrm{S}_{\min }\right)$, maximum $\left(\mathrm{S}_{\max }\right)$ and mean sensitivity indices $\left(\mathrm{S}_{\text {mean }}\right)$ of the $10 \mathrm{ANN}$ as well as the standard deviation $\sigma_{S}$ of the sensitivity indices are given in Table 3 . The results from sensitivity analysis implies that the temperature $\mathrm{T}$ and the cutting force $\mathrm{F}_{\mathrm{c}}$ were the main contributors on deformation-induced phase transformation. The passive force $F_{p}$ has a lower relevance in the model than the cutting force, but was clearly not insignificant.

\section{Testing of the models and comparison}

The two proposed models were tested in direct comparison using four data sets, which were carefully selected to cover a wide range of temperatures, process forces and resulting $\alpha^{\prime}$-martensite contents (see Fig. 10). It can be stated that the data sets which were not used in the model development could decently be estimated regarding the $\alpha^{\prime}$-martensite content depending the thermomechanical load. The estimations with the non-parametric model were closer to the measurement data than the estimation of the parametric model, which was also expected on the basis of the model predictions for already known data sets (see Figs. 7 and 9). Furthermore, it can be seen that the parametric model again

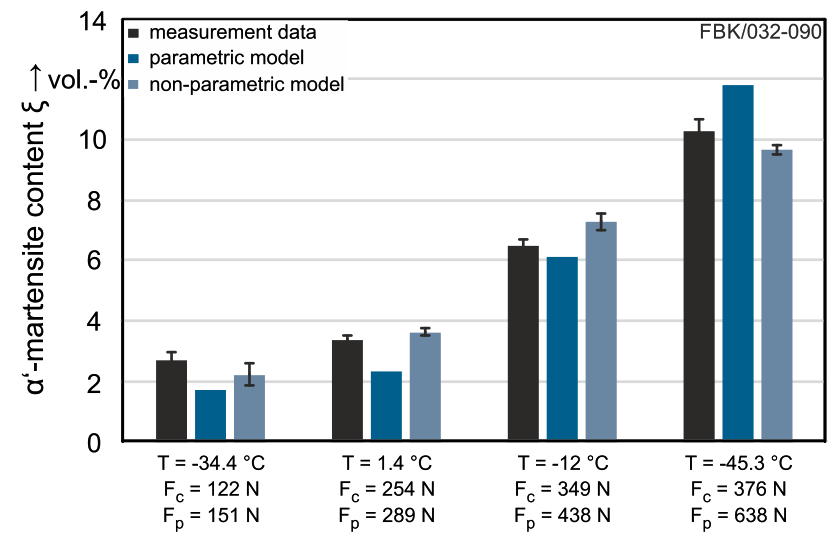

Fig. 10 Comparison of measured and calculated $\alpha^{\prime}$-martensite contents for the testing experiments

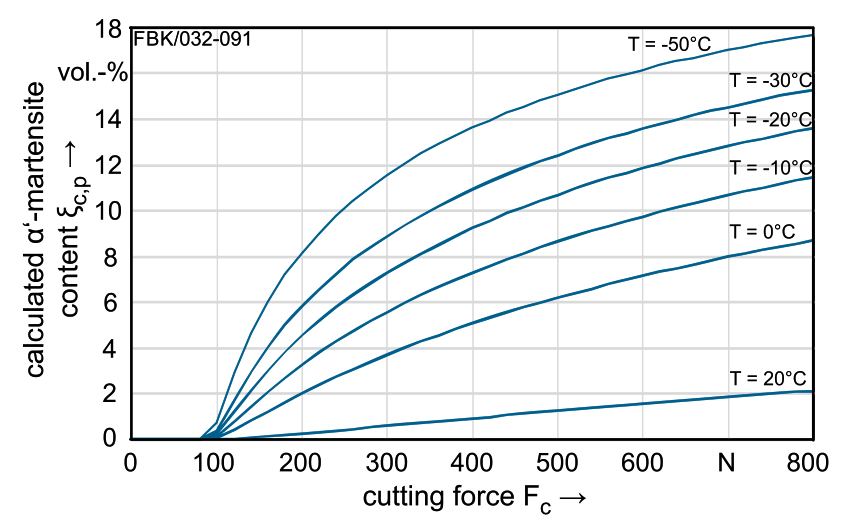

Fig. $11 \alpha^{\prime}$-martensite content depending on the cutting force and the temperature according to the parametric model

systematically underestimated low $\alpha^{\prime}$-martensite contents and overestimated high $\alpha^{\prime}$-martensite contents, whereas the small deviations of the non-parametric model seem to be random.

As both models had been proven valid, it was possible to predict the $\alpha^{\prime}$-martensite content at specific thermomechanical load. For this purpose, calculations were carried out with both models depending on the cutting force at different levels of constant temperatures. The resulting isotherms are plotted in Fig. 11 for the parametric model and in Fig. 12 for the non-parametric model. In the non-parametric model, the premise, that the passive force increases proportional with the cutting force according to the trend line describing the correlation between the two forces, was implemented for comparability with the predictions of the parametric model.

Outside the investigated test frame $\left(\mathrm{F}_{\mathrm{c}}<106 \mathrm{~N}\right.$ and $\mathrm{F}_{\mathrm{c}}>445 \mathrm{~N}$ ) the model predictions were subject to increasing uncertainty. Furthermore, the isotherms $-50{ }^{\circ} \mathrm{C}$ and $20^{\circ} \mathrm{C}$ were also less reliable than the predictions at medium temperatures due to the lower data density. This could be 


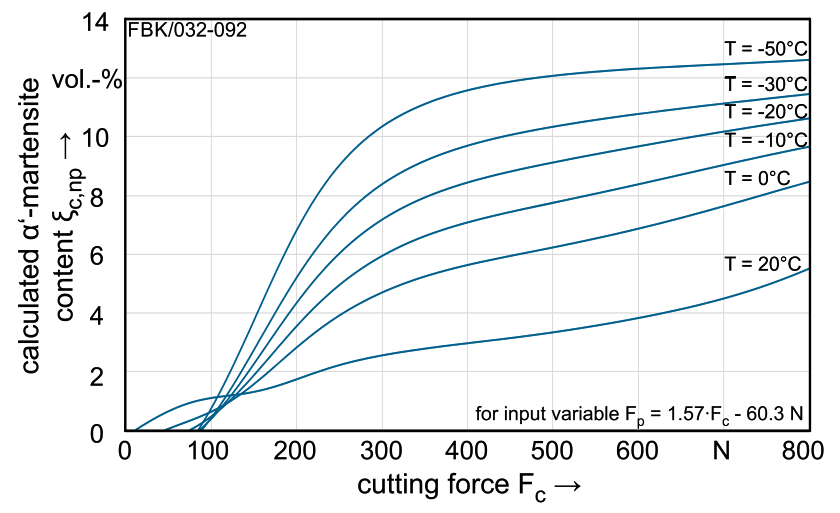

Fig. $12 \alpha^{\prime}$-martensite content depending on the cutting force and the temperature according to the non-parametric model

observed well with the rising standard deviation between the different predictions of the $10 \mathrm{ANN}$, which was not plotted for better readability. As the non-parametric model is purely data driven, negative $\alpha^{\prime}$-martensite contents were sometimes predicted when extrapolating at low cutting forces $\mathrm{F}_{\mathrm{c}}<106 \mathrm{~N}$, which of course cannot be correct. In the parametric model the exponent of the e-function was always negative, therefore the model predictions cannot be less than zero. It can be seen in the non-parametric model that at most temperatures the predicted $\alpha^{\prime}$-martensite contents become positive when surpassing a threshold slightly below a cutting force of $100 \mathrm{~N}$, which is in good agreement with the fitting parameter $b=92 \mathrm{~N}$ representing this threshold in the parametric model (see Eq. 13). In the parametric model the increase of most isotherms, but especially at higher temperatures, was less steep than in the non-parametric model, which again points to the systematic underestimation of the parametric model at low $\alpha^{\prime}$-martensite contents. In the nonparametric model there was a more pronounced saturation at high cutting forces, at which a further increase of the cutting force at constant temperature caused only a slight increase of the $\alpha^{\prime}$-martensite content.

\section{Discussion}

The high correlation coefficient $r=0.987$ between the measured $\alpha^{\prime}$-martensite content $\xi_{\mathrm{m}}$ and the $\alpha^{\prime}$-martensite content $\xi_{\mathrm{c}, \mathrm{np}}$, calculated with the non-parametric model (see Fig. 9) demonstrates on the one hand that the number of data sets and the quality of the measured data was sufficient and on the other hand that there is a high correlation between the thermomechanical load and the $\alpha^{\prime}$-martensite content formed in the workpiece subsurface during cryogenic turning. In order for this high correlation to be used as a benchmark for the parametric model, the non-parametric model must be generalizable as a premise. In other words, the used training data sets shall not be overfitted, but the model must be applicable to new data. This was realized by means of an early stopping routine and further tested with unknown data sets. The implementation of the process forces, the temperatures and the calibration curve were identified as potential sources of error in the parametric model. In the non-parametric model these errors do not occur due to the data driven approach, which led to the overall better model performance.

\section{Impact of the mechanical load}

It was found, that an increase in the passive force $\mathrm{F}_{\mathrm{p}}$ and the cutting force $\mathrm{F}_{\mathrm{c}}$ led to an increase in the $\alpha^{\prime}$-martensite formation. Within the investigated test frame, the cutting force $F_{c}$ was of higher importance, which can be evaluated in its higher overall correlation to the $\alpha^{\prime}$-martensite content (see Fig. 6), the higher sensitivity index in the non-parametric model (see Table 3) and the fact that its implementation in the parametric model led to much better results than the implementation of the passive force. However, the global sensitivity analysis proved, that the passive force $F_{p}$ contributes to the deformation induced phase transformation as well. This could also be proven by training ANN without input neurons for the passive force $F_{p}$ (MLP 2-4-1), which otherwise had the same architecture and learning algorithm. The $\alpha^{\prime}$-martensite contents determined with this reduced model only led to a correlation coefficient of only $r=0.955$ when compared to the measurement data, which demonstrates the significance of the passive force.

The parametric and the non-parametric model both imply that the cutting force must surpass a certain threshold in order to cause deformation-induced phase transformation. This is in good agreement with the results of Das et al. (2011a) and Ishimaru et al. (2015), who both presented diagrams with sigmoidal functions of the $\alpha^{\prime}$-martensite content depending on the applied stress, which must surpass a threshold before deformation-induced phase transformation occurs.

While the passive force causes deformation and thus deformation-induced phase transformation in its acting direction, or in other words right underneath the tool. The cutting forces on the other hand cause deformations and thus deformation-induced phase transformation in cutting force direction. The area spanned by these two force vectors is the preliminary deformation zone, in which the phase transformation occurs, whereby the $\alpha^{\prime}$-martensite distribution depends on the ratio of the two forces. Material in 
the preliminary deformation zone within a distance up to $200 \mu \mathrm{m}$ from the surface will be removed by via the chip as this was the constant depth of cut in our investigations. If deformation-induced phase transformation occurs in the near-surface material of the preliminary deformation zone, the microhardness will significantly increase before the material reaches the primary shear zone. The material with a higher phase fraction of $\alpha^{\prime}$-martensite and thus higher microhardness then requires higher cutting forces for shearing. In other words: not only does the cutting force impact the deformation induced phase transformation, but a higher $\alpha^{\prime}$-martensite content in the preliminary deformation zone also influences the cutting forces. These interacting influences caused the high correlation coefficients between $\alpha^{\prime}$-martensite content and cutting forces. However, the cutting force alone cannot contribute to effective subsurface hardening. The passive force must be sufficiently high so that $\alpha^{\prime}$-martensite is formed in greater depths from the surface within the preliminary deformation zone in order not to be removed by the chip. With increasing passive force, the transformation depth and the hardness penetration depth also increase, as has already been experimentally proven (Hotz and Kirsch, 2020).

Due to the above described interactions, the cutting force is nevertheless better suited as input variable in the models for estimating the mean $\alpha^{\prime}$-martensite content of the workpiece subsurface. However, it can be assumed that if the depth of cut would be significantly increased, the cutting force could no longer be a good indicator for the deformation-induced phase transformation. In this case, the passive force would presumably be of greater significance. As the subsurface hardening integrated in the cryogenic turning process is intended as finishing operation of a component, cases with high depth of cut are not industrially relevant.

\section{Impact of the thermal load}

As expected and in good agreement with the fundamentals of materials science (see Sect. 2), low temperatures favor the formation of deformation-induced formation of $\alpha^{\prime}$-martensite, which can be clearly seen in the isotherms of both models (see Figs. 11 and 12). The local maximum temperature measured with thermocouples in a borehole at a distance of one millimeter below the surface at the time of the tool contact served as a good input variable for the models as can be determined from the high correlation coefficient in the non-parametric model. While in this model the best possible consideration on the influence of temperature on deformation-induced $\alpha^{\prime}$-martensite formation was found in a data driven approach, the temperature sensitivity in the parametric model was implemented via the parameters $\alpha$ and $\beta$ (see Eqs. 11 and 12). These parameters from the model of Olson and Cohen (1975) represent the rate of shear band formation and the probability of nucleation at a shear band intersection. These parameters are not only depending on the temperature but also the austenite stability of the investigated material. Thus, when using parameters from literature (Hecker et al., 1982), errors occur because a different batch of the metastable austenitic steel was used and the influence of the deviation of the austenite stability was not taken into account. However, we were able to achieve a better model performance with the parameters of Hecker et al. (1982) than with those used by Angel (1954) and Olson and Cohen (1975), suggesting that the batch of metastable austenitic steel we used was more similar to that of Hecker et al. (1982) in terms auf austenite stability.

When implementing the parameters $\alpha$ and $\beta$ as additional input neurons in the non-parametric model (MLP 5-4-1) no improvement of the model performance could be realized. In a global sensitivity analysis, low mean sensitivity indices of $S_{\text {mean }}=1.97$ for $\alpha$ and $S_{\text {mean }}=2.46$ for $\beta$ were found. This demonstrates that these parameters are not insignificant for determining the $\alpha^{\prime}$-martensite content, but have a significantly lower impact than the temperature $\mathrm{T}$ with $\mathrm{S}_{\text {mean }}=6.84$.

For high cutting forces $F_{c}$, saturation of $\alpha^{\prime}$-martensite occurs, which can best be seen in the isotherms in Fig. 12 . Hence, at high cutting forces, a further increase of the cutting force only leads to a minor increase of the $\alpha^{\prime}$-martensite content. The saturation level decreases with increasing temperature which is in good agreement with the results shown in Fig. 2 by Angel (1954), Olson and Cohen (1975) and Hecker et al. (1982). The lower saturation level at higher temperatures is, according to Olson and Cohen (1975), due to the lower probability of $\alpha^{\prime}$-martensite nucleation on a shear band intersection, which is represented with the parameter $\beta$ in the parametric model. At room temperature $\left(\mathrm{T}=20^{\circ} \mathrm{C}\right)$ only a very small amount of deformationinduced $\alpha^{\prime}$-martensite is generated (see Figs. 11 and 12). This is the reason why conventional metal working fluids do not cause a significant phase transformation in the workpiece subsurface during turning as they are not able to decrease the temperature of the workpiece below room temperature. Hence, for generating high amounts of $\alpha^{\prime}$-martensite, cryogenic cooling must be used, which will consequently lead to an effective surface layer hardening. 


\section{Perspectives and restrictions}

The calculation of the $\alpha^{\prime}$-martensite content as a function of the thermomechanical load can be used for indirect measurement of the $\alpha^{\prime}$-martensite content during cryogenic turning. By integrating material science models that quantify the influence of the $\alpha$ ' martensite content on microhardness and fatigue properties, these workpiece properties could also be monitored in-situ during cryogenic turning.

Disturbance variables occurring during turning (such as increasing tool wear) cause a change in process forces and temperatures. The resulting deviations of the expected $\alpha$ ' martensite content can now be detected in-situ by the soft sensor. The development and implementation of a control loop would allow to compensate the control deviation by adjusting the process parameters (e.g. cutting parameters or $\mathrm{CO}_{2}$ mass flow) and thus to produce robust, pre-defined surface morphologies.

A current limitation of the proposed models is that only the mean $\alpha^{\prime}$-martensite content of a workpiece can be estimated. However, when manufacturing large components, time-related variations in the process forces and especially the temperature will most likely occur, which will lead to locally depending variations in the resulting $\alpha^{\prime}$-martensite content. Furthermore, the workpiece requires for eroded boreholes in order to insert the thermocouples, which is not conceivable in an industrial application. Both challenges could be overcome by using thermographic measurements as input variable for the thermal load, because in this way the temperature can be measured location-dependently and non-destructively. However, it is currently still difficult to reliable determine the temperature in this way, because the cryogenic $\mathrm{CO}_{2}$ in the machine room and variations in room temperature have a major influence on the measurement result. Current developments in measurement technology are working towards making this measurement method more robust, which could represent a further milestone in the implementation of surface layer soft sensors for industrial applications. Another promising approach might be to estimate the workpiece temperature depending on the measured process forces with proven models from literature and use these calculated temperatures as input variables for the models proposed in this article.

\section{Conclusion}

Based on the results presented in this paper, it can be concluded, that the content of $\alpha^{\prime}$-martensite generated in the workpiece subsurface during cryogenic turning is highly dependent on the thermomechanical load during the process. A parametric and a non-parametric model were developed in order to predict the $\alpha^{\prime}$-martensite content as a function of the temperatures and the process forces. It was found that increasing passive forces and cutting forces favored the deformation-induced formation of $\alpha^{\prime}$-martensite, whereas the feed force had no significant influence. At a constant temperature, increasing cutting forces led to sigmoidal increases in the $\alpha^{\prime}$-martensite content, whereby a threshold must be surpassed first in order for the deformation-induced phase transformation to occur. It was furthermore found that increasing temperatures inhibit the deformation-induced phase transformation and thus lead to lower saturation levels of $\alpha^{\prime}$-martensite. This demonstrates the importance of cryogenic cooling for an effective hardening of the workpiece subsurface when turning metastable austenitic steels. The obtained models can be used to estimate the $\alpha^{\prime}$-martensite content during the machining process by means of in-situ measurement of process forces and temperatures.

Acknowledgements Open Access funding provided by Projekt DEAL. This work was supported by the Deutsche Forschungsgemeinschaft (DFG, German Research Foundation) — Project Number 172116086SFB 926. ${ }^{1}$ Naming of specific manufacturers is done solely for the sake of completeness and does not necessarily imply an endorsement of the named companies nor that the products are necessarily the best for the purpose.

Open Access This article is licensed under a Creative Commons Attribution 4.0 International License, which permits use, sharing, adaptation, distribution and reproduction in any medium or format, as long as you give appropriate credit to the original author(s) and the source, provide a link to the Creative Commons licence, and indicate if changes were made. The images or other third party material in this article are included in the article's Creative Commons licence, unless indicated otherwise in a credit line to the material. If material is not included in the article's Creative Commons licence and your intended use is not permitted by statutory regulation or exceeds the permitted use, you will need to obtain permission directly from the copyright holder. To view a copy of this licence, visit http://creativecommons .org/licenses/by/4.0/. 
Appendix

\begin{tabular}{|c|c|c|c|c|c|c|c|c|c|c|c|c|c|}
\hline \multirow[t]{2}{*}{ Data set } & \multicolumn{6}{|c|}{ Input variables } & \multicolumn{4}{|c|}{ Thermomechanical load } & \multicolumn{3}{|c|}{$\alpha^{\prime}$-martensite content } \\
\hline & Coating & f & $\mathrm{K}$ & $\mathrm{r}_{\beta}$ & $\gamma_{\beta}$ & $\mathrm{f}_{\mathrm{pc}}$ & $F_{p}$ & $\mathrm{~F}_{\mathrm{c}}$ & $\mathrm{F}_{\mathrm{f}}$ & $\mathrm{T}$ & $\xi_{\mathrm{m}}$ & $\xi_{\mathrm{c}, \mathrm{p}}$ & $\xi_{\mathrm{c}, \mathrm{np}}$ \\
\hline Train & - & 0.35 & 0.5 & 30 & 0 & - & 269 & 238 & 60 & -1.1 & 3.35 & 2.44 & 3.37 \\
\hline Train & - & 0.35 & 0.5 & 90 & 0 & - & 426 & 314 & 86 & 11.9 & 3.73 & 1.44 & 3.62 \\
\hline Train & - & 0.35 & 1 & 30 & 0 & - & 257 & 235 & 55 & -0.6 & 3.18 & 2.33 & 3.09 \\
\hline Train & - & 0.35 & 1 & 60 & 0 & - & 285 & 242 & 61 & 0.0 & 3.14 & 2.36 & 3.54 \\
\hline Train & - & 0.35 & 1 & 90 & 0 & - & 291 & 248 & 64 & 0.5 & 3.55 & 2.39 & 3.66 \\
\hline Train & - & 0.35 & 2 & 30 & 0 & - & 240 & 224 & 51 & -1.4 & 3.14 & 2.26 & 2.74 \\
\hline Train & - & 0.35 & 2 & 60 & 0 & - & 283 & 239 & 63 & -1.6 & 3.91 & 2.53 & 3.62 \\
\hline Train & - & 0.35 & 2 & 90 & 0 & - & 291 & 244 & 63 & 2.1 & 4.07 & 2.11 & 3.45 \\
\hline Train & - & 0.35 & 1 & 4 & 20 & - & 284 & 240 & 58 & -0.6 & 3.54 & 2.41 & 3.56 \\
\hline Train & AlTiN & 0.15 & 1 & 8 & 20 & - & 171 & 124 & 50 & -34.2 & 2.63 & 1.87 & 2.83 \\
\hline Train & Multilayer & 0.15 & 1 & 27 & 20 & - & 177 & 135 & 50 & -31.4 & 3.02 & 2.35 & 2.85 \\
\hline Train & TiAlSiN & 0.15 & 1 & 11 & 20 & - & 191 & 144 & 48 & -25.5 & 2.78 & 2.39 & 2.89 \\
\hline Val & $\mathrm{TiB}_{2}$ & 0.15 & 1 & 5 & 20 & - & 182 & 129 & 49 & -29.9 & 2.81 & 1.88 & 2.89 \\
\hline Train & - & 0.15 & 1 & 4 & 20 & - & 186 & 144 & 49 & -32.0 & 2.91 & 2.87 & 3.15 \\
\hline Train & - & 0.35 & 1 & 32 & 0 & - & 246 & 232 & 53 & -0.4 & 2.97 & 2.26 & 2.83 \\
\hline Val & - & 0.35 & 1 & 32 & 0 & - & 241 & 230 & 55 & -17.5 & 3.81 & 4.51 & 4.05 \\
\hline Train & - & 0.35 & 1 & 32 & 0 & - & 241 & 232 & 54 & -10.3 & 3.35 & 3.59 & 3.45 \\
\hline Train & - & 0.35 & 1 & 32 & 0 & - & 246 & 235 & 56 & -3.1 & 3.06 & 2.66 & 3.03 \\
\hline Train & - & 0.35 & 1 & 32 & 0 & - & 251 & 232 & 56 & -1.2 & 2.10 & 2.36 & 2.99 \\
\hline Train & - & 0.15 & 1 & 4 & 30 & - & 195 & 128 & 51 & -18.9 & 3.26 & 1.24 & 2.58 \\
\hline Train & - & 0.15 & 1 & 4 & 50 & - & 346 & 188 & 73 & -21.2 & 4.61 & 3.71 & 4.68 \\
\hline Train & - & 0.35 & 1 & 4 & 0 & 0.274 & 215 & 196 & 47 & -30.4 & 4.07 & 5.02 & 4.04 \\
\hline Val & - & 0.35 & 1 & 4 & 30 & 0.274 & 453 & 355 & 51 & -41.3 & 10.42 & 10.88 & 10.71 \\
\hline Train & - & 0.65 & 1 & 4 & 30 & 0.203 & 721 & 433 & 57 & -44.7 & 10.03 & 12.70 & 10.12 \\
\hline Train & - & 0.65 & 1 & 4 & 50 & 0.203 & 511 & 279 & 84 & -36.0 & 8.49 & 8.37 & 7.35 \\
\hline Train & - & 0.65 & 1 & 4 & 0 & 0.203 & 520 & 425 & 48 & -40.7 & 11.82 & 12.06 & 11.90 \\
\hline Train & - & 0.95 & 1 & 4 & 30 & 0.186 & 291 & 220 & 51 & -41.4 & 7.40 & 7.17 & 7.30 \\
\hline Val & - & 0.95 & 1 & 4 & 50 & 0.186 & 304 & 307 & 47 & -42.7 & 7.65 & 9.97 & 8.35 \\
\hline Train & - & 0.95 & 1 & 4 & 0 & 0.186 & 369 & 385 & 42 & -43.0 & 10.19 & 11.67 & 10.48 \\
\hline Val & - & 0.65 & 1 & 4 & 0 & 0.4 & 302 & 311 & 47 & -19.1 & 6.91 & 6.65 & 6.39 \\
\hline Train & - & 0.65 & 1 & 4 & 50 & 0.4 & 644 & 384 & 78 & -27.5 & 8.07 & 9.43 & 7.66 \\
\hline Train & - & 0.65 & 1 & 4 & 30 & 0.4 & 435 & 344 & 56 & -12.3 & 7.73 & 6.12 & 7.22 \\
\hline Val & - & 0.45 & 1 & 4 & 30 & 0.8 & 349 & 269 & 26 & -6.2 & 5.63 & 3.73 & 5.03 \\
\hline Train & - & 0.85 & 1 & 4 & 30 & 0.8 & 507 & 411 & 55 & -4.6 & 6.62 & 5.60 & 7.34 \\
\hline Train & - & 0.65 & 1 & 4 & 50 & 0.4 & 626 & 382 & 88 & -22.3 & 7.47 & 8.54 & 7.15 \\
\hline Train & - & 0.65 & 1 & 4 & 50 & 0.8 & 616 & 389 & 87 & -8.3 & 5.28 & 6.06 & 5.63 \\
\hline Val & - & 0.45 & 1 & 4 & 50 & 0.8 & 524 & 316 & 90 & -7.0 & 5.35 & 4.68 & 4.79 \\
\hline Train & - & 0.85 & 1 & 4 & 50 & 0.8 & 700 & 445 & 69 & -7.9 & 5.71 & 6.74 & 5.86 \\
\hline Train & - & 0.35 & 1 & 4 & 50 & 0.15 & 482 & 265 & 75 & -54.8 & 8.18 & 10.21 & 9.34 \\
\hline Train & - & 0.35 & 1 & 4 & 50 & 0.8 & 485 & 283 & 83 & -14.1 & 4.41 & 5.26 & 5.21 \\
\hline Train & - & 0.65 & 1 & 4 & 50 & 0.15 & 636 & 367 & 75 & -49.1 & 9.95 & 12.08 & 9.89 \\
\hline Train & - & 0.85 & 1 & 4 & 50 & 0.15 & 686 & 420 & 62 & -41.6 & 9.94 & 12.10 & 9.82 \\
\hline Train & - & 0.45 & 1 & 4 & 50 & 0.15 & 543 & 302 & 78 & -50.0 & 8.55 & 10.73 & 9.24 \\
\hline Train & - & 0.35 & 1 & 4 & 30 & 0.15 & 300 & 232 & 59 & -4.0 & 2.78 & 2.72 & 3.88 \\
\hline Train & - & 0.35 & 1 & 4 & 30 & 0.15 & 290 & 216 & 51 & -52.5 & 8.63 & 8.26 & 8.25 \\
\hline Train & - & 0.35 & 1 & 4 & 30 & 0.8 & 295 & 223 & 56 & -25.3 & 6.40 & 5.33 & 5.83 \\
\hline Train & - & 0.65 & 1 & 4 & 30 & 0.15 & 415 & 326 & 51 & -46.0 & 11.23 & 10.83 & 10.61 \\
\hline
\end{tabular}




\begin{tabular}{|c|c|c|c|c|c|c|c|c|c|c|c|c|c|}
\hline \multirow[t]{2}{*}{ Data set } & \multicolumn{6}{|c|}{ Input variables } & \multicolumn{4}{|c|}{ Thermomechanical load } & \multicolumn{3}{|c|}{$\alpha^{\prime}$-martensite content } \\
\hline & Coating & $\mathrm{f}$ & $\mathrm{K}$ & $\mathrm{r}_{\beta}$ & $\gamma_{\beta}$ & $\mathrm{f}_{\mathrm{pc}}$ & $\mathrm{F}_{\mathrm{p}}$ & $\mathrm{F}_{\mathrm{c}}$ & $F_{f}$ & $\mathrm{~T}$ & $\xi_{\mathrm{m}}$ & $\xi_{\mathrm{c}, \mathrm{p}}$ & $\xi_{\mathrm{c}, \mathrm{np}}$ \\
\hline Train & - & 0.85 & 1 & 4 & 30 & 0.15 & 477 & 398 & 48 & -46.0 & 12.38 & 12.29 & 12.09 \\
\hline Train & - & 0.45 & 1 & 4 & 30 & 0.15 & 340 & 261 & 54 & -48.8 & 9.77 & 9.42 & 9.29 \\
\hline Train & - & 0.15 & 1 & 4 & 0 & 0.15 & 134 & 106 & 35 & -62.6 & 2.47 & 1.49 & 2.95 \\
\hline Train & - & 0.45 & 1 & 4 & 0 & 0.15 & 245 & 239 & 46 & -51.1 & 6.72 & 8.96 & 6.67 \\
\hline Test & $\mathrm{TiN}$ & 0.15 & 1 & 3 & 20 & - & 151 & 122 & 40 & -34.4 & 2.68 & 1.72 & 2.19 \\
\hline Test & - & 0.35 & 0.5 & 60 & - & - & 289 & 254 & 62 & 1.4 & 3.38 & 2.34 & 3.65 \\
\hline Test & - & 0.65 & 1 & 4 & 30 & 0.8 & 438 & 349 & 57 & -12.0 & 6.46 & 6.14 & 7.34 \\
\hline Test & - & 0.35 & 1 & 4 & 50 & 0.274 & 638 & 376 & 76 & -45.3 & 10.26 & 11.79 & 9.71 \\
\hline
\end{tabular}

Nomenclature: feed rate $\mathrm{f}$ in $\mathrm{mm} / \mathrm{rev}$, cutting edge radius $\mathrm{r}_{\beta}$ in $\mu \mathrm{m}$, formfactor $\mathrm{K}$ of the cutting edge, feed rate during precooling $\mathrm{f}_{\mathrm{pc}}$ in $\mathrm{mm} / \mathrm{rev}$, passive force $\mathrm{F}_{\mathrm{p}}$ in $\mathrm{N}$, cutting force $\mathrm{F}_{\mathrm{c}}$ in $\mathrm{N}$, Feed force $\mathrm{F}_{\mathrm{f}}$ in $\mathrm{N}$, Temperature $\mathrm{T}$ in ${ }^{\circ} \mathrm{C}$, measured $\alpha^{\prime}$-martensite content $\xi_{\mathrm{m}}$ in vol\%, $\alpha^{\prime}$-martensite content calculated with parametric model $\xi_{\mathrm{c}, \mathrm{p}}$ in vol\%, $\alpha^{\prime}$-martensite content calculated with non-parametric model $\xi_{\mathrm{c}, \mathrm{np}}$ in vol\%

\begin{tabular}{|c|c|c|c|c|c|c|c|c|c|c|}
\hline ANN & 1 & 2 & 3 & 4 & 5 & 6 & 7 & 8 & 9 & 10 \\
\hline Epoch & 29 & 111 & 48 & 33 & 61 & 107 & 191 & 85 & 186 & 37 \\
\hline Function hidden layer & $\exp$ & $\tanh$ & $\tanh$ & $\tanh$ & $\tanh$ & $\exp$ & $\exp$ & $\exp$ & $\log$ & $\tanh$ \\
\hline Function output layer & $\tanh$ & $\log$ & id & id & id & $\exp$ & id & id & $\exp$ & id \\
\hline \multicolumn{11}{|l|}{ Weights hidden layer } \\
\hline wil,h1 & -0.19 & 7.13 & -0.75 & 0.45 & 0.70 & 1.21 & 0.31 & 0.00 & -1.32 & -0.32 \\
\hline wi1,h2 & -6.97 & -7.16 & 3.02 & -0.66 & -1.73 & -10.65 & -3.63 & 1.03 & 1.48 & -2.94 \\
\hline wi1,h3 & 3.28 & -10.18 & -1.01 & 0.20 & 1.06 & 2.54 & 2.07 & -0.40 & -1.97 & 0.82 \\
\hline wil,h4 & -0.28 & 6.23 & 0.61 & -0.55 & 0.26 & 0.92 & -0.41 & 0.20 & 1.76 & -0.48 \\
\hline wi2,h1 & 1.04 & -2.38 & 0.67 & 0.46 & -2.16 & -1.30 & -1.33 & -1.20 & -8.87 & 0.55 \\
\hline wi2,h2 & 0.32 & 0.89 & -0.71 & -0.14 & 0.70 & 0.78 & 0.08 & 0.53 & 4.86 & 0.07 \\
\hline wi2,h3 & -0.41 & -4.55 & -0.24 & 0.20 & 0.65 & 1.20 & -2.39 & 0.77 & -19.37 & -0.01 \\
\hline wi2,h4 & 0.89 & -6.33 & 0.68 & 0.17 & 1.92 & -3.13 & 7.44 & -0.14 & 7.08 & -0.02 \\
\hline wi3,h1 & 0.99 & 0.31 & -0.74 & -0.09 & -7.17 & 1.21 & -3.05 & 1.39 & -5.75 & -0.73 \\
\hline wi3,h2 & 0.54 & -0.38 & 0.25 & 1.38 & 3.33 & -0.16 & 1.79 & -0.45 & -9.22 & 1.01 \\
\hline wi3,h3 & 1.08 & 0.32 & 0.44 & -0.30 & -0.26 & 3.98 & -0.37 & 0.17 & 2.09 & -0.58 \\
\hline wi3,h4 & 1.19 & 5.50 & -1.60 & -3.34 & 2.75 & -1.12 & 2.31 & 2.37 & -11.77 & 0.42 \\
\hline \multicolumn{11}{|l|}{ Weights output layer } \\
\hline wh1,o1 & -0.25 & -14.04 & 0.33 & 0.78 & -0.99 & -0.95 & 3.94 & -1.14 & 21.18 & 1.59 \\
\hline wh2,o1 & 0.03 & 9.92 & 0.77 & -0.76 & -1.07 & 2.33 & 1.92 & 1.00 & -1.42 & -1.00 \\
\hline wh3,o1 & 2.10 & 4.73 & 1.16 & -0.34 & 0.52 & -1.97 & 0.00 & 3.74 & -1.93 & 0.26 \\
\hline wh4,o1 & -0.55 & -0.75 & 1.23 & 1.24 & -1.24 & -0.56 & -0.70 & 1.93 & -28.89 & -1.34 \\
\hline \multicolumn{11}{|l|}{ Bias hidden layer } \\
\hline bh1 & -0.43 & 0.20 & 0.39 & -1.49 & -0.42 & -4.04 & 2.05 & 1.55 & -17.71 & -0.14 \\
\hline bh2 & -0.46 & 0.77 & 0.50 & 0.12 & -0.15 & -0.36 & -0.49 & -1.01 & 1.94 & 0.09 \\
\hline bh3 & -0.10 & -4.31 & -0.24 & 0.55 & 0.48 & -0.14 & -0.35 & 0.79 & 0.41 & -0.10 \\
\hline bh4 & 0.26 & 0.61 & -0.11 & 0.87 & 0.78 & 1.48 & 3.64 & -0.36 & -3.79 & -0.06 \\
\hline \multicolumn{11}{|l|}{ Bias output layer } \\
\hline bo1 & -1.01 & -1.69 & 0.01 & 0.21 & 0.06 & 0.07 & -5.21 & -4.40 & 0.39 & 0.35 \\
\hline
\end{tabular}

Nomenclature: exponential function (exp), hyperbolic tangent (tanh), identity function (id), logistic sigmoid (log). 


\section{References}

Ahmedabadi, P. M., Kain, V., \& Agrawal, A. (2016). Modelling kinetics of strain-induced martensite transformation during plastic deformation of austenitic stainless steel. Materials and Design, $109,466-475$.

Angel, T. (1954). Formation of martensite in austenitic stainless steels-Effect of deformation, temperature, and composition. Journal of the Iron Steel Institute, 177, 165-174.

Aurich, J. C., Mayer, P., Kirsch, B., Eifler, D., Smaga, M., \& Skorupski, R. (2014). Characterization of deformation induced surface hardening during cryogenic turning of AISI 347. CIRP AnnalsManufacturing Technology, 63(1), 65-68.

Becker, S., Hotz, H., Kirsch, B., Aurich, J. C., Harbou, E., \& Müller, R. (2018). A finite element approach to calculate temperatures arising during cryogenic turning of metastable austenitic steel AISI 347. ASME Journal of Manufacturing Science and Engineering, 140(10), 101016.

Boemke, A., Smaga, M., \& Beck, T. (2018). Influence of surface morphology on very high cycle fatigue behavior of metastable and stable austenitic Cr-Ni steels. MATEC Web of Conferences, 165, 20008.

Bolling, G. F., \& Richman, R. H. (1970). The plastic deformationtransformation of paramagnetic f.c.c Fe-Ni-C alloys. Acta Metallurgica, 18(6), 673-681.

Brinksmeier, E., Meyer, D., Heinzel, C., Lübben, T., Sölter, J., Langenhorst, L., et al. (2018). Process signatures-The missing link to predict surface integrity in machining. Procedia CIRP, 71, 3-10.

Broyden, C. G. (1970). The convergence of a class of double-rank minimization algorithms 1 . General consideration. Journal of the Institute of Mathematics and Its Applications, 6(1), 76-90.

Choudhary, A. K., Harding, J. A., \& Tiwari, M. K. (2009). Data mining in manufacturing: A review based on the kind of knowledge. Journal of Intelligent Manufacturing, 20, 501. https://doi.org/10.1007/ s10845-008-0145-x.

Das, A., Tarafder, S., \& Chakraborti, P. C. (2011a). Estimation of deformation induced martensite in austenitic stainless steels. Materials Science and Engineering A, 529, 9-20.

Das, A., Chakraborti, P. C., Tarafder, S., \& Bhadeshia, H. K. D. H. (2011b). Analysis of deformation induced martensitic transformation in stainless steels. Materials Science and Technology, 27(1), 366-370.

Eichelmann, G. C., \& Hull, T. C. (1953). The effect of composition on the temperature of spontaneous transformation of austenite to martensite in 18-8 type stainless steel. Transactions of the American Society for Metals, 45, 77-104.

Fletcher, R. (1970). A new approach to variable metric algorithms. Computer Journal, 13(3), 317-322.

Frölich, D., Magyar, B., Sauer, B., Mayer, P., Kirsch, B., Aurich, J. C., et al. (2015). Investigation of wear resistance of dry and cryogenic turned metastable austenitic steel shafts and dry turned and ground carburized steel shafts in the radial shaft seal ring system. Wear, 328-329, 123-131.

Garbrecht, M. (2006). Mechanisches Randschichthärten in der Fertigung. Germany: University of Bremen.

Goldfarb, D. (1970). A family of variable metric updates derived by variational means. Mathematics of Computation, 24(109), 23-26.

Hecker, S. S., Stout, M. G., Staudhammer, K. P., \& Smith, J. L. (1982). Effects of strain rate on deformation-induced transformation in 304 stainless steel: Part I. Magnetic measurements and mechanical behavior. Metallurgical Transactions A, 13, 619-626.

Herper, H. C. (2000). Ab-initio-Untersuchung magnetischer und struktureller Eigenschaften von 3D-Übergangsmetallen und ihren Legierungen. Germany: University of Duisburg.
Hotz, H., Kirsch, B., Becker, S., Harbou, E., Müller, R., \& Aurich, J. C. (2018). Modification of surface morphology during cryogenic turning of metastable austenitic steel AISI 347 at different parameter combinations with constant $\mathrm{CO} 2$ consumption per cut. Procedia CIRP, 77, 207-210.

Hotz, H., \& Kirsch, B. (2020). Influence of tool properties on thermomechanical load and surface morphology when cryogenically turning metastable austenitic steel AISI 347. Journal of Manufacturing Processes, 52, 120-131.

Huang, G. L., Matlock, D. K., \& Krauss, G. (1989). Martensite formation, strain rate sensitivity, and deformation behavior of type 304 stainless steel sheet. Metallurgical Transactions A, 20, 1239-1246.

Huang, Y., \& Liang, S. Y. (2003). Modelling of the cutting temperature distribution under the tool flank wear effect. Proceedings of the Institution of Mechnical Engineers, Part C: Journal of Mechanical Engineering Science, 217(11), 1195-1208.

Ishimaru, E., Hamasaki, H., \& Yoshida, F. (2015). Deformationinduced martensitic transformation behavior of type 304 stainless steel sheet in draw-bending process. Journal of Materials Processing Technology, 223, 34-38.

Jawahir, I. S., Brinksmeier, E., M'Saoubi, R., Aspinwall, D. K., Outeiro, J. C., Meyer, D., et al. (2011). Surface integrity in material removal processes: Recent advances. CIRP Annals-Manufacturing Technology, 60, 603-626.

Jawahir, I. S., Attia, H., Biermann, D., Duflou, J., Klocke, F., Meyer, D., et al. (2016). Cryogenic manufacturing processes. CIRP Annals-Manufacturing Technology, 65, 713-736.

Ji, W., Yin, S., \& Wang, L. (2019). A big data analytics based machining optimisation approach. Journal of Intelligent Manufacturing, 30, 1483-1495.

Kirsch, B., Hotz, H., Müller, R., Becker, S., Boemke, A., Smaga, M., et al. (2019). Generation of deformation-induced martensite when cryogenic turning various batches of the metastable austenitic steel AISI 347. Production Engineering, 13, 343-350.

Komanduri, R., \& Hou, Z. B. (2000). Thermal modeling of the metal cutting process: Part I-Temperature rise distribution due to shear plane heat source. International Journal of Mechanical Sciences, 42(9), 1715-1752.

Lagneborg, R. (1964). The martensite transformation in $18 \% \mathrm{Cr}-8 \%$ Ni steels. Acta Metallurgica, 12, 823-843.

Mangonon, P. L., Jr., \& Thomas, G. (1970). Structure and properties of thermally-mechanically treated 304 stainless steel. Metallurgical Transactions, 1(6), 1587-1594.

Mayer, P., Kirsch, B., Müller, C., Hotz, H., Müller, R., Becker, S., et al. (2018). Deformation induced hardening wehen cryogenic turning. CIRP Journal of Manufacturing Science and Technology, 23, 6-19.

Nohara, K., Ono, Y., \& Ohashi, N. (1977). Composition and grain size dependencies of strain-induced martensite transformation in metastable austenitic steels. Journal of Iron and Steel Institute of Japan, 63(5), 772-782.

Olson, G. B., \& Cohen, M. (1972). A mechanism for the strain-induced nucleation of martensitic transformations. Journal of Less Common Metals, 28(1), 107-118.

Olson, G. B., \& Cohen, M. (1975). Kinetics of strain-induced martensitic nucleation. Metallurgical Transactions A, 6, 791-795.

Outeiro, J. C., Campocasso, S., Denguir, L. A., Fromentin, G., Vignal, V., \& Poulachon, G. (2015). Experimental and numerical assessment of subsurface plastic deformation induced by OFHC copper machining. CIRP Annals, 64, 53-56.

Patel, J. R., \& Cohen, M. (1953). Criterion for the action of applied stress in the martensitic transformation. Acta Metallurgica, 1(5), 531-538.

Pati, S. R., \& Cohen, M. (1969). Nucleation of the isothermal martensitic transformation. Acta Metallurgica, 17(3), 189-199. 
Pranke, K., Wendler, M., Weidner, A., Sergey, G., Weiß, A., \& Kawalla, R. (2015). Formability of strong metastable $\mathrm{Fe}-15 \mathrm{Cr}-3 \mathrm{Mn}-3 \mathrm{Ni}-$ $0.2 \mathrm{C}-0.1 \mathrm{~N}$ austenitic TRIP/(TWIP) steel-A comparison of different base materials. Journal of Alloys and Compounds, 648, 783-793.

Rhodes, C. G., \& Thompson, A. W. (1977). The composition dependence of stacking fault energy in austenitic stainless steels. Metallurgical Transactions A, 8, 1901-1906.

Rodic, D., Sekulic, M., Gostimirovic, M., Pucovsky, V., \& Kramar, D. (2020). Fuzzy logic and sub-clustering approaches to predict main cutting force in high-pressure jet assisted turning. Journal of Intelligent Manufacturing. https://doi.org/10.1007/s10845-02001555-4.

Schumann, H. (1975). Verformungsinduzierte Martensitbildung in metastabilen austenitischen Stählen. Kristall und Technik, 10(4), 401-411.

Sharma, V. S., Dhiman, S., Sehgal, R., \& Sharma, S. K. (2008). Estimation of cutting forces and surface roughness for hard turning using neural networks. Journal of Intelligent Manufacturing, 19, 473-483.

Shanno, D. F. (1970). Conditioning of quasi-Newton methods for function minimization. Mathematics of Computation., 24(111), 647-656.

Smaga, M., Walther, F., \& Eifler, D. (2008). Deformation-induced martensitic transformation in metastable austenitic steels. Materials Science and Engineering A, 483-484, 394-397.

Staudhammer, K. P., Murr, L. E., \& Hecker, S. S. (1983). Nucleation and evolution of strain-induced martensitic (BCC) embryos and substructure in stainless-steel-A transmission electron-microscope study. Acta Metallurgica, 31(2), 267-274.

Stringfellow, R. G., Parks, D. M., \& Olson, G. B. (1992). A constitutive model for transformation plasticity accompanying strain-induced martensitic transformations in metastable austenitic steels. Acta Metallurgica Et Materialia, 40(7), 1703-1716.
Talonen, J., Aspegren, P., \& Hänninen, H. (2004). Comparison of different methods for measuring strain induced $\alpha^{\prime}$-martensite content in austenitic steels. Materials Science and Technology, 20(12), $1506-1512$.

Uebel, J., Ströer, F., Basten, S., Ankener, W., Hotz, H., Heberger, L., et al. (2019). Approach for the observation of surface conditions in-process by soft sensors during cryogenic hard turning. Procedia CIRP, 81, 1260-1265.

Venables, J. A. (1962). The martensite transformation in stainless steel The Philosophical Magazine, 7(73), 35-44.

Vöhringer, O., \& Macherauch, E. (1977). Struktur und mechanischer Eigenschaften von Martensit. HTM Journal of Heat Treatment and Materials, 32(1), 153-166.

Xu, L., Huang, C., Li, C., Wang, J., Liu, H., \& Wang, X. (2020). An improved case based reasoning method and its application in estimation of surface quality toward intelligent machining. Journal of Intelligent Manufacturing. https://doi.org/10.1007/s10845-02001573-2.

Zaera, R., Rodríguez-Martínez, J. A., Casado, A., Fernández-Sáez, J., Rusinek, A., \& Pesci, R. (2012). A constitutive model for analyzing martensite formation in austenitic steels deforming at high strain rates. International Journal of Pasticity, 29, 77-109.

Zhang, W., Wang, X., Hu, Y., \& Wang, S. (2018a). Quantitative studies of machining-induced microstructure alteration and plastic deformation in AISI 316 stainless steel using EBSD. Journal of Materials Engineering and Performance, 27(2), 434-446.

Zhang, W., Wang, X., Hu, Y., \& Wang, S. (2018b). Predictive modelling of microstructure changes, micro-hardness and residual stress in machining of 304 austenitic stainless steel. International Journal of Machine Tools and Manufacture, 130-131, 36-48.

Publisher's Note Springer Nature remains neutral with regard to jurisdictional claims in published maps and institutional affiliations. 